\title{
Neuronal Control of Bird Song Production
}

\author{
James S. McCasland \\ Beckman Laboratories of Behavioral Biology, Division of Biology 216-76, California Institute of Technology, Pasadena, \\ California 91125
}

\begin{abstract}
Bird song represents a powerful model system for many of the important problems in behavioral neurobiology, offering both easily measured sensory and motor patterns and a discrete neural effector system. Methods were developed to record the discharge of neurons in singing birds to examine the functions of nuclei in the song control pathway previously implicated anatomically. In several cases, lesions and other techniques were employed to test predictions derived from electrode recordings. Four major findings emerge from these studies. (1) Single-unit recordings from telencephalic nucleus hyperstriatum ventrale, pars caudale (HVc) show several classes of neurons with apparently specialized roles in song production and/or sensorimotor interaction. (2) The nucleus interfacialis (NIf; Nottebohm, 1980), which provides an input to HVc and is anatomically the "highest" nucleus in the descending motor pathway, is uniquely placed among vocal control nuclei to be a generator of timing cues for song. (3) Consistent with the unidirectlonal connections between nuclei of the descending pathway, NIf, HVc, and nucleus robustus archistriatalis (RA) are activated sequentially prior to sound onset. Three other nuclei with connections to or from the descending tract do not show song-related activity in the adult. (4) Bilateral HVC recordings and peripheral disruptions of the vocal apparatus suggest that both hemispheres and syringeal halves normally make similar contributions to most if not all song syllables. The latter finding casts doubt on the analogy between neural lateralization in bird song and in human speech.
\end{abstract}

\footnotetext{
Received Aug. 21, 1985; revised May 27, 1986; accepted June 10, 1986.

I wish to thank my thesis advisor, Dr. Masakazu Konishi, for his support through every phase of this project and for performing the surgeries for the bronchusplugging experiments. Many thanks are also owed to Drs. Andy Moiseff, Eric Knudsen, and Terry Takahashi for numerous helpful discussions of work and manuscripts. Expert histological assistance and advice were provided by Gene Akutagawa, and Cindy Akutagawa assisted in animal care. Mike Walsh, Dave Hodge, and John Power provided electronics expertise and equipment.

Secretarial assistance was provided by the staff in the Beckman offices-Candi Hochenedel, Caren Oto, Nancy Gill, Chris Balber, and Kathy O'Loughlin. Margo E. Gross (secretarial) and Joseph Hayes (photographic) assisted in revisions of the manuscript and figures.

This work was supported by National Research Service Awards 5 T01 GM00086 and 5 T32 GM07737, by National Institutes of Health Grant 5 R01 NS14617, NINCDS-NIH Grants 5 T 32 NS07057 and P01 NS17763, and by the Weigle Memorial Fund, the Pew Memorial Fund, and the McDonnell Center for Studies of Higher Brain Function.

Portions of this work have appeared in preliminary form [Konishi, M. (1985) Annu. Rev. Neurosci. 8: 125-170.]

Correspondence should be addressed to James S. McCasland, Ph.D., James $\mathbf{L}$. O'Leary Division of Experimental Neurology and Neurological Surgery, Washington University School of Medicine, 660 South Euclid Avenue, St. Louis, MO 63110.

Copyright (c) 1987 Society for Neuroscience $0270-6474 / 87 / 010023-17 \$ 02.00 / 0$
}

The acquisition of song in birds exemplifies an early sensory experience manifested as a motor pattern later in life. Bird song exhibits the phenomena of behavioral development and learning as shown by the effects of sensory exposure, deprivation, and isolation, by inborn perceptual preferences, and by a critical impressionable period. A complex pattern of neuromuscular coordination underlies bird song, and this pattern is learned in many species (Thorpe, 1958; Marler and Tamura, 1964; Marler, 1970). Thus, song offers a particularly favorable opportunity to study how complex motor programs are developed, stored, and executed by the brain.

The neural system for song control (Fig. 1), a discrete chain of nuclei and fiber tracts, was discovered (Nottebohm et al., 1976) through lesion experiments that implicated these structures in normal song production. Nottebohm et al.'s discovery opened the way to the study of the acquisition and maintenance of a complex motor program by a neural system. Among the outstanding issues not resolved by these experiments are the theories concerning hemispheric dominance (Nottebohm, 1971, 1972), the mechanisms of song production, and song learning.

Until recently, lesion experiments provided the only means of assessing the roles of various brain areas in song. The present paper describes the results of single-unit and multiunit recordings from singing birds. The aim of these studies was to examine directly the temporal roles played by various nuclei in song production. The combination of multiunit and single-unit techniques enabled both the detection of neurons with specialized roles in song production, as wcll as sampling the activities of substantial numbers of neurons in different brain nuclei for songrelated activity. In several instances the recordings suggested hypotheses that were tested by means of brain lesions or other disruptive techniques, including disturbances of the peripheral motor apparatus.

\section{Materials and Methods}

Subjects. Birds of 4 species (zebra finches, Poephilia guttata; mockingbirds, Mimus polyglottos; white-crowned sparrows, Zonotrichia leucophrys; and canaries, Serinus canarius) were used for these experiments. The numbers of successful recording experiments are indicated in Table 1. Additional subjects were used in developing the recording techniques, and in the lesion and bronchus-plugging studies discussed in the text, bringing the total number of birds studied to 140 . Wasserschlager canaries, a breed thought to be highly lateralized (Nottebohm and Nottebohm, 1976), were bred from a stock donated by Dr. Peter Marler of the Rockefeller University. Other breeds of canaries and zebra finches (slightly lateralized: Price, 1977) were purchased from local breeders. Whitecrowned sparrows (lateralized: Nottebohm and Nottebohm, 1976, Nottebohm, 1977) and mockingbirds (no published evaluations of lateralization) were raised by hand from the nestling stage. The birds were individually housed in sound-attenuation chambers (Industrial Acoustics, Bronx, NY)

Multiple-unit recordings. Neural recordings of multiple-unit activity 


\section{A. Behavior}
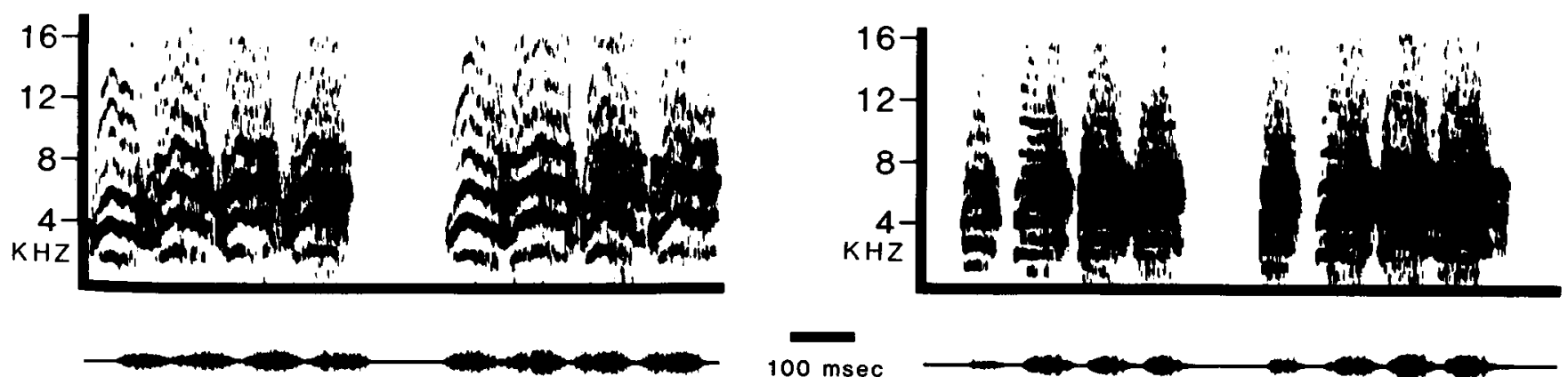

$100 \mathrm{msec}$

B. Pathway

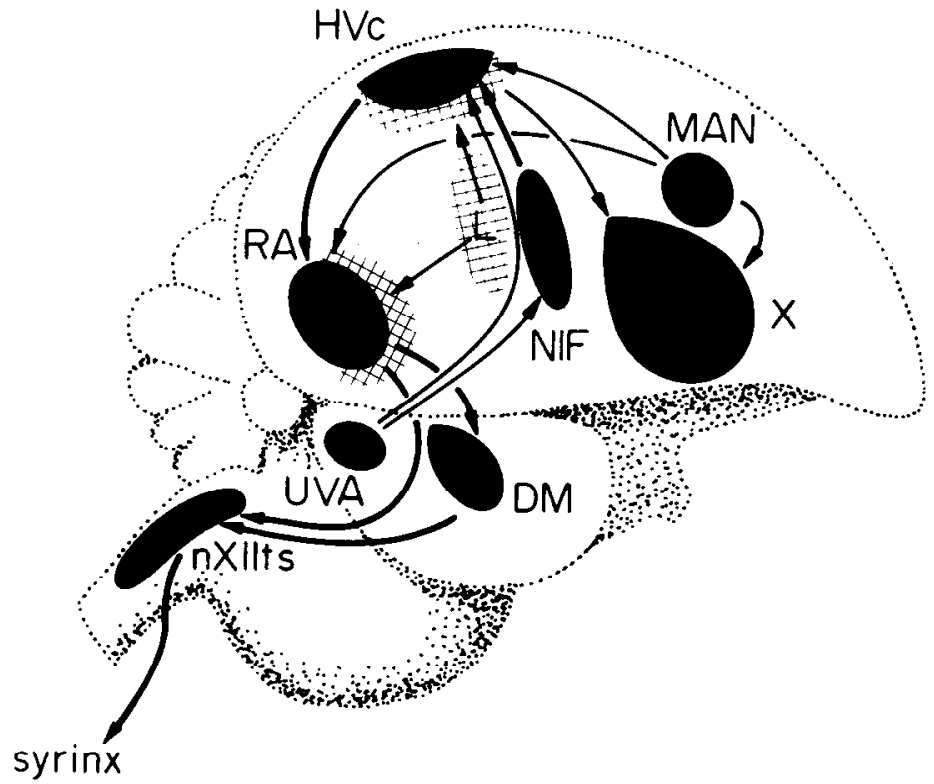

\section{C.Syrinx}

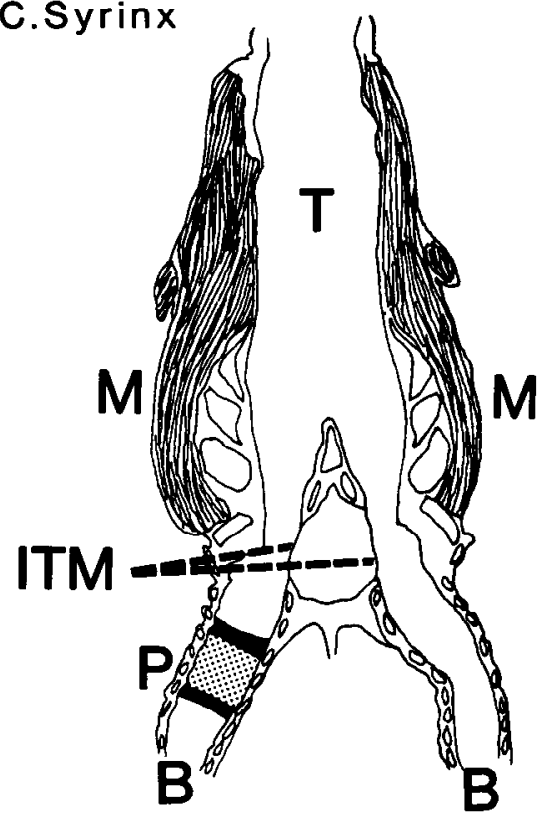

Figure 1. The birdsong neuromuscular system. $A$, Sonagrams (upper panel) showing the spectral composition of sound versus time and corresponding oscillograms (lower traces) of 2 mockingbird song episodes. Oscillograms correspond to sonagrams. Each syllable consists of a frequencymodulated fundamental and several harmonics. For most illustrative purposes it is more convenient to present oscillograms in conjunction with single-unit or multiunit recordings. $B$, Schematic diagram of the vocal control system in songbirds. Arrows indicate anterograde connections between nuclei. Lesion studies have shown HVc (hyperstriatum ventrale, pars caudale) and RA (n. robustus archistriatalis) are necessary for normal song production. Hatched areas represent auditory pathways. Other abbreviations: NIf, nucleus interfacialis; $n X I I t s$, n. hypoglossus, pars tracheosyringealis; $M A N$, magnocellular nucleus of the anterior neostriatum; $X$, Area $\mathrm{X} ; D M$, dorsomedial nucleus of nucleus intercollicularis; $U V A$, thalamic nucleus uva. $C$, Canary syrinx viewed from behind, with surgically placed plug ( $P$, see text) inserted in left bronchus $(B)$. The left and right internal tympaniform membranes (ITM) are thought to be the primary oscillators for song production; note the position of the plug below the ITM in the left bronchus. The left-right asymmetry in the intrinsic musculature $(M)$ is exaggerated for emphasis. $T$, lumen of trachea. (After Nottebohm and Nottebohm, 1976.)

reliably show the activity and the temporal discharge pattern of many neurons (McCasland and Konishi, 1981). In order to make ncuronal recordings from the brains of singing birds, it was necessary to overcome 2 major technical obstacles. First, because bird song has a territorial and reproductive role in the natural behavior of birds and is largely refractory to behavioral conditioning, it was necessary to create conditions under which birds would sing while restrained by a recording cable. With repeated sessions most healthy subjects produced songs, but the typical recording session produced songs of a total duration far less than $1 \%$ of the length of the session. This problem was exacerbated by the difficulties encountered in targeting electrodes successfully for the deeper song control nuclei (stereotaxic targeting in our experience being somewhat unreliable despite the existence of atlases).

The second major obstacle involves "movement" artifacts associated with singing. Such artifacts are prevalent in loud singers such as the mockingbird and canary but can be virtually climinated by a coaxial electrode constructed as follows. A length of 33 or 34 gauge stainless steel tubing was electrically etched to a tapered tip in $50 \%$ sulfuric acid. An insulated $\mathrm{NiCr}$ wire, $62 \mu \mathrm{m}$ in diameter, was then inserted in the tubing, and this assembly was coated with Stoner Mudge lacquer (Mobil Oil). The wire was cut flush with the tapered end of the tube and the tip rounded. The wire and tube were connected to separate sockets of a miniature connector. The electrode assembly was then stereotaxically implanted in subjects anesthetized with Equithesin.

For recording sessions, flexible cables were used to connect the electrodes to a differential amplifier. Implanted subjects sang following one or more sessions of adapting to the cables. Singing was induced in each experimental bird by subcutaneous implantation of $5 \mathrm{mg}$ testosterone proprionate (Schering Co.). When necessary, birds were induced to sing by removal of their mates or by placing another male nearby. Vocalizations and neural activity were recorded simultaneously on magnetic tape (Teac 3340S, $19 \mathrm{~cm} / \mathrm{sec}$ ). Songs produced after electrode placement were comparcd with preoperative songs to ensure that no deficits had resulted from the implantation procedures. Sound recordings were ana- 

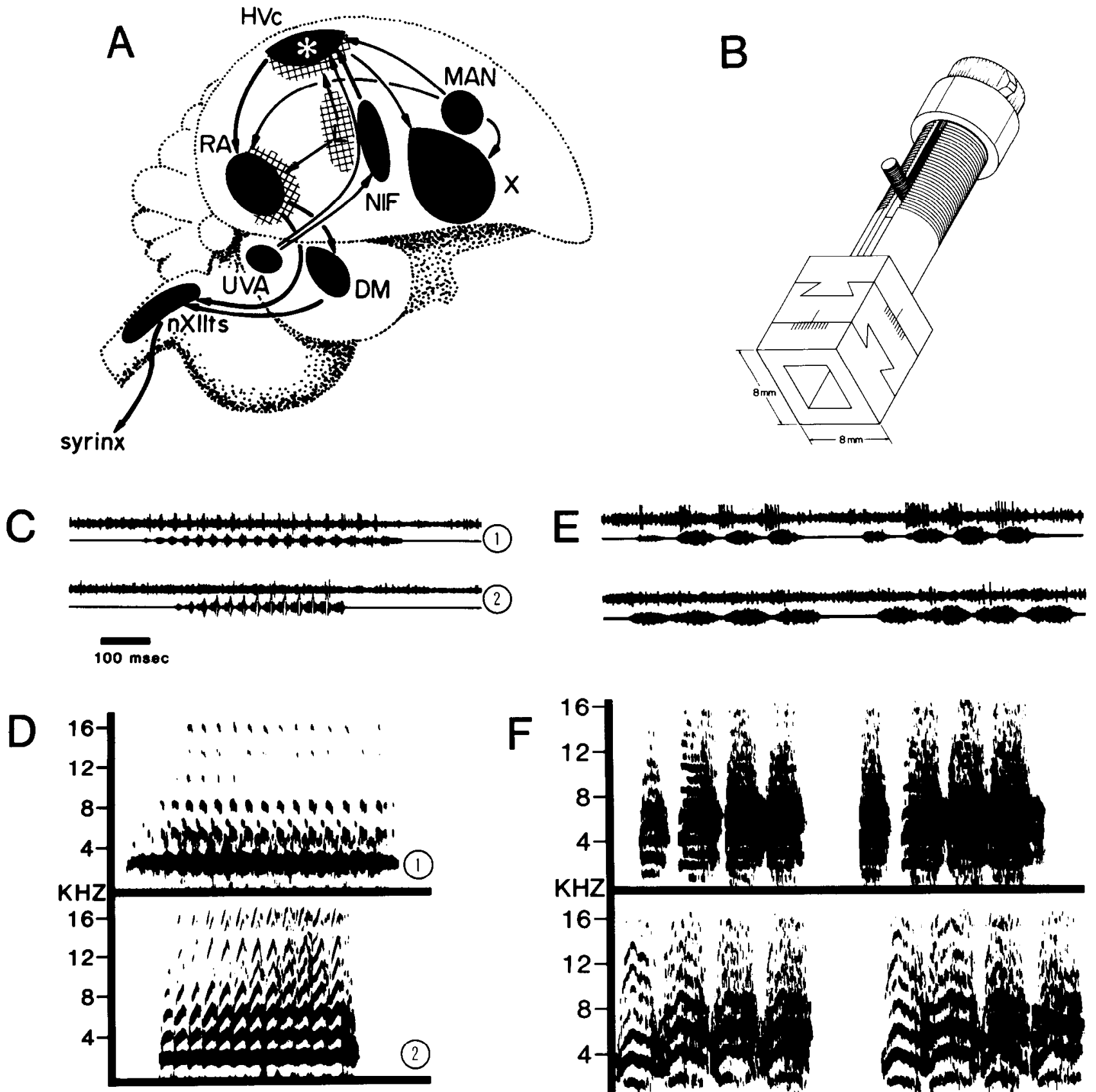

$100 \mathrm{msec}$

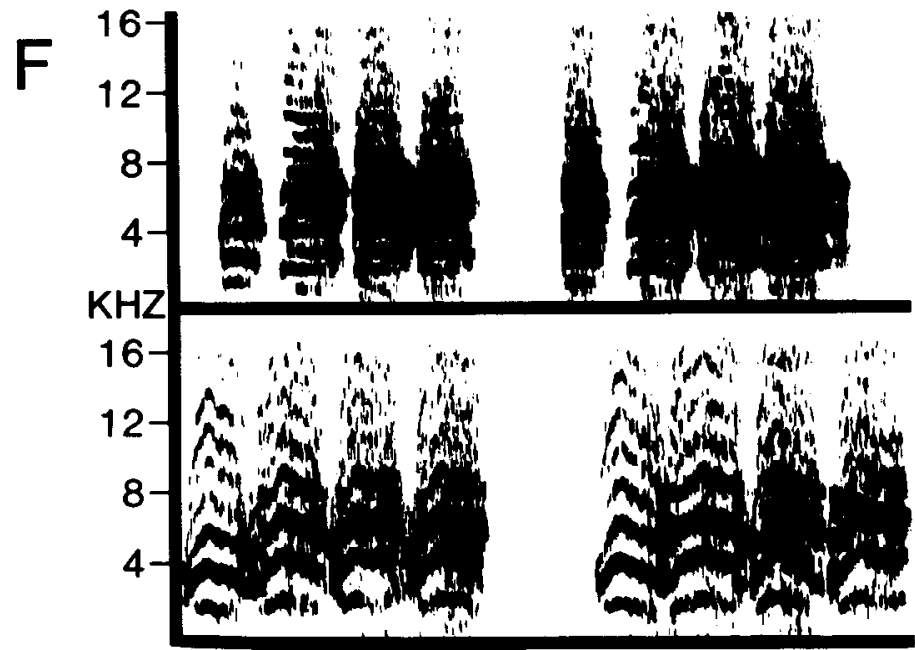

Figure 2. Recordings showing specialized roles of individual neurons in song production. $A$, Summary anatomical diagram of the song control system. Asterisk indicates nucleus from which recordings were made (left $\mathrm{HVc}$ in the mockingbird). (For abbreviations see legend to Fig. 1.) $B$, Miniature implanted electrode microdrive used to make single-unit recordings. The microdrive consists of two stages: a tower that advances the electrode and an $X-Y$ base that positions the electrode for each new track. The tower stage consists of a removable cap for changing electrodes, a top-mounted dial for advancing the electrode in controlled steps, and a core in which threads on the inner surface of an outer screw, which is rotated by the top dial, turn against the threads of an inner screw. As a result, the inner screw, within which the electrode is rigidly held, can be advanced or retracted without itself rotating. The electrode shaft is housed within this inner screw, and rigidly fixed to it by a screw that serves as contact for recording purposes. The $X-Y$ base of the microdrive consists of two sliding stages with dovetails cut at right angles, each with a set screw. These stages allow movement of the tower assembly in 2 planes, so that the electrode can be positioned over any point in a $16 \mathrm{~mm}^{2}$ area (inner working area). Other details as described in Materials and Methods. C, Single-unit recordings (upper traces in 1 and 2 ) corresponding to oscillograms (lower traces) of 2 repeated syllables produced by the bird. Sonagrams of the syllables are shown in $D(l$ and 2$)$. Both song segments are similar to canary trills heard often during rearing by this mockingbird, suggesting that both are cases of interspecific mimicry for which the mockingbird is well known. This unit produced a discrete burst of activity time-locked to each syllable in the upper train (except the first and last, which are relatively undifferentiated), while producing almost no spikes for the lower trill. The unit did not respond to tape playback of either the upper or lower trill. $E$ and $F$, Another example of a selective motor unit that did not show auditory responses to the same sounds. The repeated syllables in upper and lower records, the same as those shown in Figure 1, were both similar to zebra finch syllables heard often by this mockingbird. The unit produced bursts of activity for only the upper syllables. Time bar in $C$ applies to $C-F$. 
Table 1. Song-related recording sites in different birds

\begin{tabular}{|c|c|c|c|c|c|c|}
\hline \multirow[b]{2}{*}{ Structure } & \multicolumn{2}{|c|}{ Zebra finch } & \multicolumn{2}{|c|}{ Canary } & \multicolumn{2}{|c|}{ Total } \\
\hline & $\begin{array}{l}\text { Left } \\
\mathrm{h} .\end{array}$ & $\begin{array}{l}\text { Right } \\
\text { h. }\end{array}$ & $\begin{array}{l}\text { Left } \\
\text { h. }\end{array}$ & $\begin{array}{l}\text { Right } \\
\text { h. }\end{array}$ & $\begin{array}{l}\text { Left } \\
\text { h. }\end{array}$ & $\begin{array}{l}\text { Right } \\
\text { h. }\end{array}$ \\
\hline NIF & 1 & 1 & 0 & 0 & 1 & 1 \\
\hline $\mathrm{HVc}$ & 4 & 5 & 3 & 6 & 7 & 11 \\
\hline RA & 7 & 2 & 0 & 1 & 7 & 3 \\
\hline Area X & 1 & 1 & 1 & 0 & 2 & 1 \\
\hline MAN & 1 & 1 & 0 & 0 & 1 & 1 \\
\hline Uva & 1 & 2 & 0 & 0 & 1 & 2 \\
\hline Total & 15 & 12 & 4 & 7 & 19 & 19 \\
\hline
\end{tabular}

One set of multiunit recordings from left HVc of the white-crowned sparrow and 1 set of single-unit recordings from left $\mathrm{HVc}$ of the mockingbird bring the grand total of recording sites to 40 . Other experiments and numbers of subjects are described in the text. $h$., hemisphere.

lyzed with a Kay Electric Co. model 7029A sound spectrograph $(8 \mathrm{kHz}$ range, narrow-band setting). Correlations between vocal and neural activities were examined by displaying them simultaneously on either a storage oscilloscope or on paper film made with a Grass Instrument model C4L kymograph camera. Electrode locations were verified by identifying electrolytic lesions in Nissl-stained $50 \mu \mathrm{m}$ frozen serial sections. Histograms of multiunit events were prepared with programs written by Dr. Andy Moiseff on a PDP11-40 computer; individual sweeps for these histograms were triggered by the output of a soundlevel detector from tape-recorded sounds.

Single-unit recordings. The multiunit recordings obtained with the above techniques often showed spikes of quite high (5:1) signal-to-noise ratios. However, identifying the activities of single neurons was very difficult and unreliable, even with a voltage-and-time-window discriminator. Accordingly, with the aid of expert machinist Herb Adams a miniature microdrive (Fig. 2), which could be chronically mounted on the heads of large songbirds such as the mockingbird, was designed and constructed. The microdrive consists of 2 stages: a tower that advances the electrode and an $X-Y$ base for positioning the electrode. The towcr stage has a removable cap for changing electrodes, a top-mounted dial for advancing the electrode in controlled steps, and a core in which threads on the inner surface of an outer screw, which is rotated by the top dial, turns against the threads of an inner screw. As a result, the inner screw, within which the electrode is rigidly held, can be advanced or retracted without itself rotating. The electrode shaft is housed within this inner screw and is rigidly fixed to it by a screw that serves as contact for recording purposes. A short, flexible lead wire, cemented to the set screw with silver epoxy (Amicon, Lexington, MA), connects the electrode to a contact assembly (Microtech, Boothwyn, PA). A gold pin serves as a differential electrode for recording purposes. The $X-Y$ base of the microdrive consists of 2 sliding stages with dovetails cut at right angles, each with a set screw. These stages allow movement of the tower asscmbly in 2 plancs, so that the electrode can be positioned over any point in a $16 \mathrm{~mm}^{2}$ area. The electrodes were constructed from a length of $150 \mu \mathrm{m} \mathrm{Pt}-\mathrm{Ir}$ rod, electrically etched in cyanide or chlorine bleach solution to a blunt tip (E. V. Evarts, personal communication), then thinly coated with the appropriate solder glass (Corning) (Wolbarsht et al., 1960). A tip of approximately $6-10 \mu \mathrm{m}$ was exposed by passing negative current through it in a saline solution; tips were inspected microscopically with the aid of a fiber optics light source (Dyonics, Woburn, MA).

The microdrive was implanted, with the subject under anesthesia, after removing the skull over the area of interest; care was taken to avoid damage to the dura. The microdrive assembly, including the electrode, was then positioned over the exposed brain area and affixed to the skull with dental cement applied around the microdrive base. The contact plug, preassembled with the gold pin for differential contact, was then positioned anterior to the microdrive and cemented, with the gold pin contacting the dura, at an angle corresponding to the vertical in the freely behaving bird. For recording sessions a commutator prevented coiling of the recording cable. Other details of recording sessions and data analysis are as described above.

Playback experiments. Auditory stimulus presentations for interaction studies consisted of tape-recorded vocalizations, typically the bird's own song, played through an audio amplifier and loudspeaker. Playback sound amplitude was monitored with a VU meter and could be matched to the sound amplitude of the original song or varied. Sound propagation time from the speaker to the bird's head was never more than 2 msec. The size of the recording chamber $(60 \times 50 \times 50 \mathrm{~cm})$ ensured a relatively uniform sound field around the bird and minimized disparities in sound intensity at the bird's own ear between playback stimuli and sounds produced by the bird.

Bronchus plugging. The birds were anesthetized and secured (anterior side up) on a small operating platform. The bronchi were exposed through a midline incision in the interclavicular air sac, which surrounds the syrinx and was easily located by following the trachea into the thoracic cavity. As soon as the thin membrane of the air sac was cut, the syrinx became visible through a Zeiss operating microscope. The syrinx was deflected to one side to visualize the bronchus of the opposite side under the syringeal musculature with a sharpened forceps. An incision was made between bronchial rings with the syrinx under traction well below $(0.5-1 \mathrm{~mm})$ the lower edge of the internal tympaniform membrane (see Fig. 1). The tapered plug was a $1 \mathrm{~mm}$ length of small-gauge $(0.025 \mathrm{~mm}$ O.D.) polyethylene tubing packed tightly with cotton wool. After the plug was positioned in the bronchus, tapered end distally, tissue adhesive (Histoacryl, Braun Melsungen) was applied liberally, thereby holding the plug firmly in place and sealing the cotton packing to air. A meniscus of Histoacryl above the proximal end of the plug ensured that the bronchus was completely sealed. The plugs and the bronchial incision were examined at the end of each experiment. In all cases the incision had healed and the plug remained where it was placed. Sonagrams were prepared from songs recorded before and after plugging.

\section{Results}

Since frequent reference is made to the structure of bird song, a brief description of it is in order. In most species, song is the longest and most elaborate vocalization produced by the bird. It is produced predominantly by sexually mature males during breeding season and consists of temporally stereotyped sequences of individual sounds called syllables that are visualized as continuous markings on the time-frequency sound spectrogram (Fig. 1). In ethological terms, song is a largely territorial display that is usually delivered from a particular location within the territory and accompanied by a stereotyped body posture. Song can be distinguished from calls, which consist of simple, brief sounds uttered in all seasons and by both sexes. Calls are not delivered from fixed perches or associated with a specific body posture. The temporal pattern of song is characterized by the sequence and the timing in which different syllables occur and alternate with silent intervals. Many birds use fixed temporal patterns in their songs, some of which are specific for a given species or individual (cf. Fig. 1). In all songbird species studied so far, a group of brain nuclei has been implicated in different aspects of this behavior (Fig. 1B). The peripheral apparatus for song and call production is called the syrinx (Fig. $1 C$ ); unlike the larynx, this is located at the junction of the bronchi and trachea, with the consequence for lateralization studies that vocal production can be unilaterally disrupted (note plug in left bronchus in Fig. 1C).

\section{Single-unit recordings from $\mathrm{HVC}$}

Single-unit recordings can provide a means of assessing the mechanisms of neuronal firing related to song production and of sensorimotor interactions such as the motor inhibition of auditory inputs that we have observed in hyperstriatum ventrale, pars caudale ( $\mathrm{HVc}$ ) multiunit recordings (McCasland and Konishi, 1981). These considerations prompted the development of a new technique for recording from single neurons in song system nuclei of the freely behaving, singing mockingbird. The implanted $X-Y$ microdrive (Fig. 2) allows repeated electrode penetrations over a $16 \mathrm{~mm}^{2}$ area and is sufficiently stable so that units can be isolated and held for several hours.

The single-unit recordings presented here were obtained from 


\section{Premotor Specific}

\section{A. Motor General}

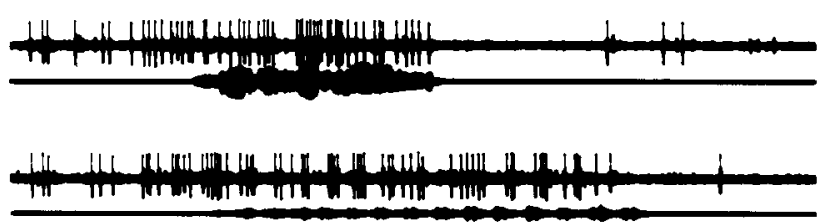

B. Motor Anticipatory

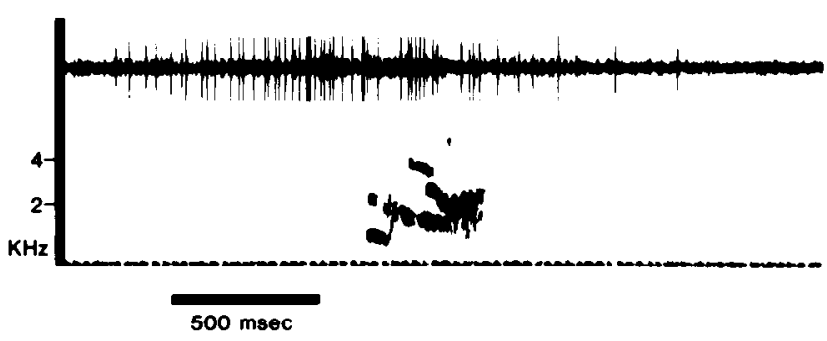

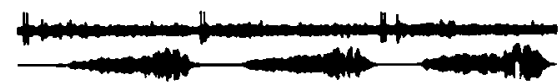
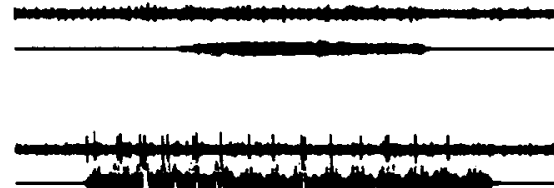

\section{Singing Premotor Specific}

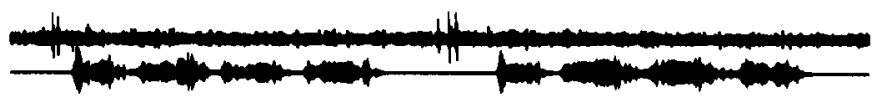

\section{Playback Inhibited}

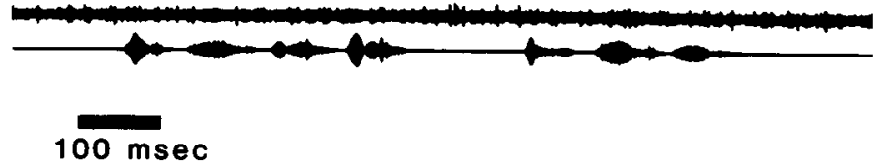

Figure 3. Single units demonstrating temporal relationships to different aspects of song production. $A$, Motor general single-unit recording from left $\mathrm{HVc}$ in the singing mockingbird that shows premotor activity for all song syllables. This unit did not respond to the same song syllables presented as auditory stimuli. Lower record shows some clustering of activity for trill elements; for comparison with more specific patterns, see $C$ and $D$ and Figure 2. $B$, Motor anticipatory single-unit activity precedes the initiation of song. Upper trace shows single-unit recording produced after a $15 \mathrm{sec}$ silent interval, just before, during, and after production of a single syllable, a sonagram of which is shown in lower portion of panel. Note the steady increase in unit activity throughout approximately a $1 \mathrm{sec}$ period leading up to sound onset, and long time bar. $C$, Premotorspecific single-unit recording: upper record, repeated syllable for which the unit in mockingbird HVc consistently fired well in advance of sound production; middle record, syllable for which the unit was silent; lower record, repeated syllable for which the unit was consistently active after sound onset, firing with a constant phase relationship to the trill elements. $D$, Example of a single-unit motor-auditory interaction. This cell exhibited premotor specificity in the singing bird by firing in advance of only a few syllables, including that shown in the upper record. During nonsinging periods, the unit was inhibited (firing rate below spontaneous activity rate) by playback of all song syllables, as illustrated in the lower record. This inhibition was statistically highly significant.

mockingbird HVc, because the superficial position of this nucleus makes it the most accessible target. The sample of neurons is small (15) but shows several classes of neurons with apparently specialized roles in song production. Four cells were found in $\mathrm{HVc}$ that showed selective motor activity; they produced highly stereotyped bursts of spikes for only a few syllables (Fig. 2). The distinctions between sounds for which these cells did or did not show activity may be quite subtle. For example, both sets of repeated syllables in Figure $2, E$ and $F$, were noticeably similar to zebra finch song syllables to which this mockingbird was repeatedly exposed during its first year (see Lanyon, 1976). Yet in 10 examples of each set of syllables the HVc unit was active only for the first set of syllables, suggesting that HVc cells may encode subtle variations in sound production. This interpretation is supported by the high degree of temporal specificity of unit firing with respect to timing of the syllable, which can be seen most clearly in Figure $2 C$. This unit fired regularly for one 1 of 2 trill segments (trains of rapidly repeated short frequencymodulated syllables), both of which were very similar to canary trills heard often by this mockingbird. There was a constant phase relationship between bursts of unit activity and individual trill elements. Because of the importance of auditory feedback in the development of song patterning (Konishi, 1965), segments of the bird's own song were played back during singing and nonsinging periods to check for auditory responses. Neither of these cells showed an auditory response to playback of the same syllables for which it produced motor activity when the bird sang.

Six cells exhibited premotor activity for all mockingbird song syllables (Fig. 3, $A$ and $B$ ) but did not respond to those samc syllables presented as auditory stimuli. Some of these cells had relatively constant presound lead times of increased activity for the various syllables, while others showed "anticipatory" activity of very long (ca. $500 \mathrm{msec}$ ) lead times prior to the initiation of song and between syllables of a long song bout (Fig. $3 B$ ). In general, these units produced relatively sporadic activity for successive repetitions of the same syllable. However, careful examination revealed consistent pattern differences corresponding to different syllables (Fig. $3 A$, lower record). In many cases these differentiated firing patterns were evident in premotor activity, some tens of milliseconds before sound onset (not shown).

The motor-specific cells described above were generally not active before the onset of sound, raising the possibility that their selective activity patterns could be due to proprioceptive or auditory feedback. However, recordings have been obtained from $2 \mathrm{HVc}$ neurons for which a feedback-based explanation of their activity patterns can be ruled out (Fig. 3, $C$ and $D$ ). 
A. UVA (Zebra Finch)

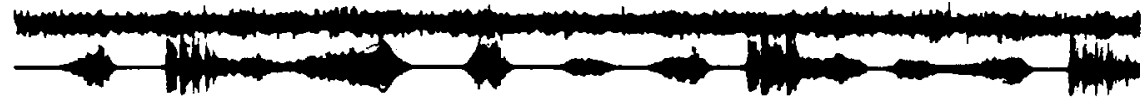

D. Key

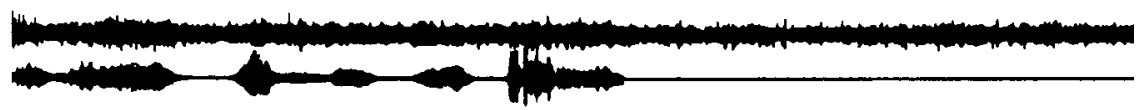

B. MAN (Zebra Finch)
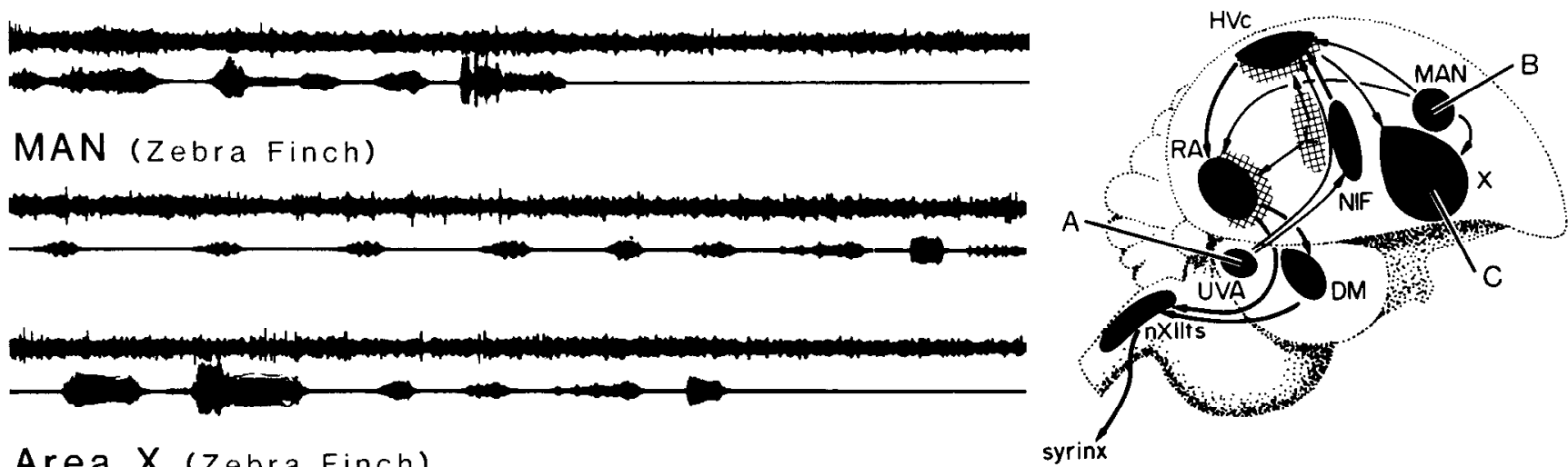

C. Area X (Zebra Finch)

syrinx
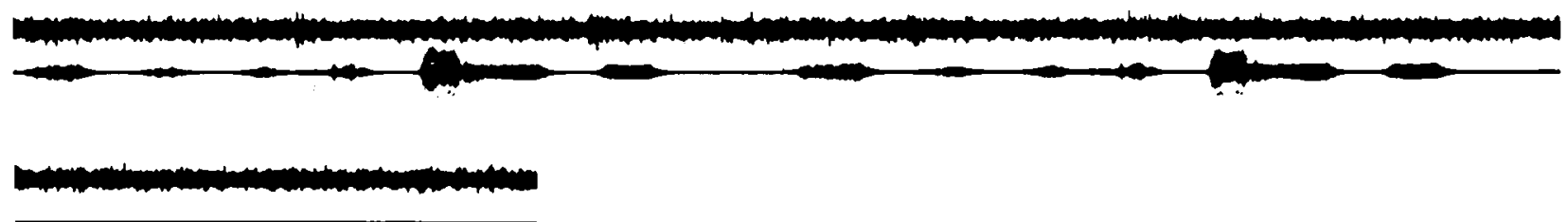

Area X (Canary)
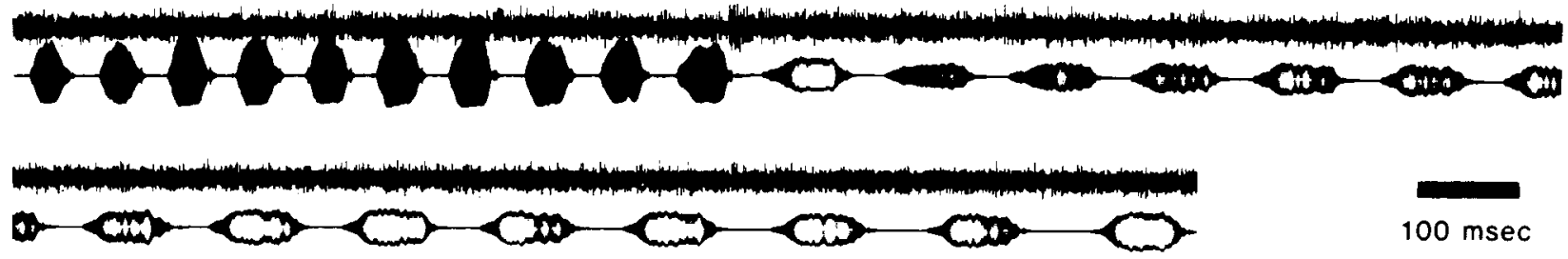

$100 \mathrm{msec}$

Figure 4. Nuclei of the song control system that do not show obvious activity time-locked to adult song. Locations as indicated in key $(D)$. $A$, Thalamic nucleus Uva provides an input to NIf and to HVc but showed no song-locked activity in the adult zebra finch. As shown in Figure $7 C$, bilateral lesions of Uva had no effect on adult song in the zebra finch. $B$, MAN provides inputs to HVc and RA but showed only baseline rates of activity during song. $C$, Area $\mathrm{X}$ receives inputs from $\mathrm{HVc}$ and MAN; this nucleus also showed baseline rates of activity during song in both the zebra finch and canary. $D$, Key showing recording sites for $A-C$. (See legend to Fig. 1 for abbreviations.)

These units consistently fired well in advance of sound onset for certain syllables and were consistently silent for other syllables. As indicated in the bottom record of Figure $3 C$, their activity for certain song elements was not restricted to pre-sound periods. Nevertheless, the fact that they fired for only certain syllables, in advance of sound production, is strong evidence for premotor specificity in these cells.

Two units showed motor-auditory interaction. One cell (Fig. $3 D$ ) showed premotor specificity by firing in advance of only a few syllables, including that shown in the upper record of Figure $3 D$. When presented with tape playback of the bird's own song during nonsinging periods, the unit was inhibited, as illustrated in the lower record. This inhibition was highly significant (2tailed $t$ test; $d f=38, p<0.001$ ). The same type of inhibition was observed in the "trill-specific" neuron shown in Figure $2 B$. Because these inhibitory responses to song playback are confined to nonsinging periods, they represent in formal terms exactly the opposite of the effect described in multiunit recordings in an earlier report (McCasland and Konishi, 1981).

Taken together, these data suggest a model of motor control of song production which is highly reminiscent of that developed by other workers for mammalian motor cortex (Evarts et al., 1984). A population of units is recruited during the general behavior patterns of vocalization; smaller sets of neurons are recruited for the more specific motor requirements in producing particular song syllables. These phenomena should be borne in mind when examining the multiunit data presented below in the context of the source of timing for song control, as well as the bilateral multiunit recordings used to examine the issues of timing and hemispheric lateralization in song control. One must expect such multiunit recordings to contain discharges from a number of specialized unit types, each functioning in a different aspect of song production and active at different times in the song cycle.

\section{Functional survey of song-related nuclei}

On the basis of previous studies using lesion-deficit and pathway-tracing techniques, 8 brain nuclei were implicated as possible control centers for song. Lesions of $\mathrm{HVc}$, nucleus robustus archistriatalis (RA), and the hypoglossal nerve produced dra- 
A NIf

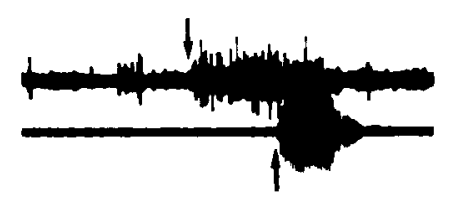

HVc

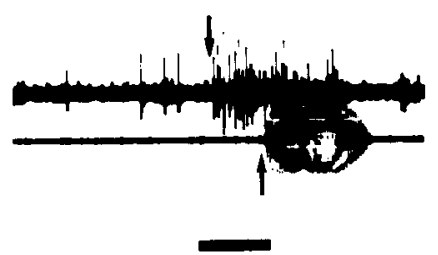

$50 \mathrm{msec}$
C NIF

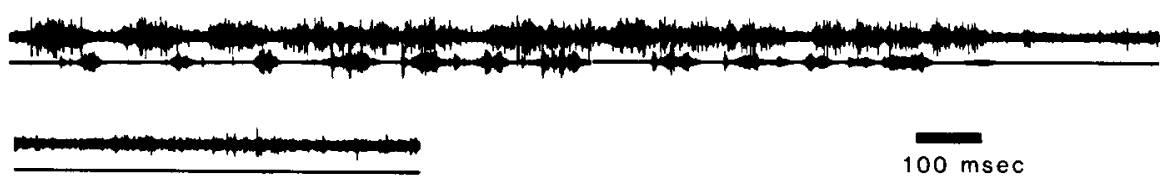

D HVc

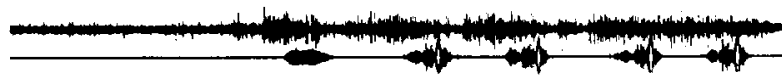

E
RA

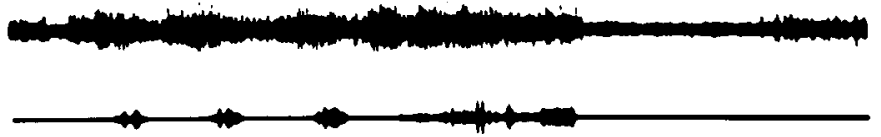

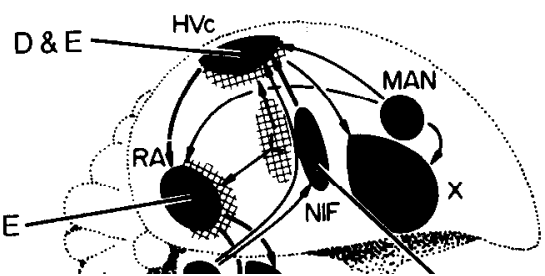

HVC

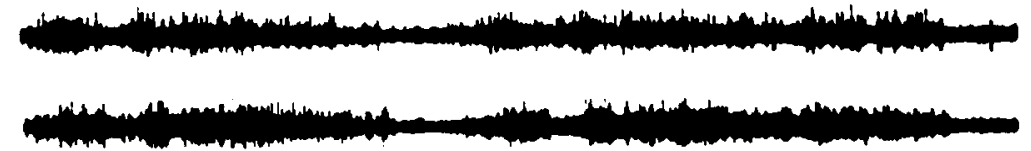

RA

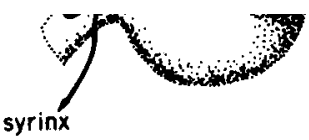

HVC

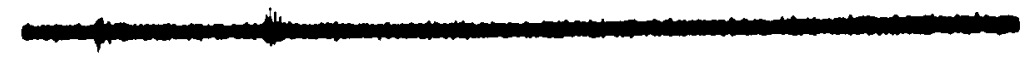

RA

Figure 5. Recordings from 3 nuclei that show song-locked activity. (Consult $B$ for locations of nuclei from which recordings were made.) $A$, Relationship between multiple-unit activity in NIf and HVc for homologous vocalizations. Upper record: Representative example of multiunit activity recorded from left NIf (upper trace) and a contact call (lower trace) produced by a zebra finch. Lower record: Representative case of multiunit activity recorded from left $\mathrm{HVc}$ of a second bird during production of a homologous contact call. Arrows above and below indicate onset times for vocalization-related neural activity and sound production, respectively. Lead time for such activity was approximately 60 msec for NIf and about $50 \mathrm{msec}$ for HVc. For a histogram comparison of similar data, see Figure 6. B, Key for recording locations. $C$, Continuous multiple-unit neural recordings from NIf of the singing zebra finch. Upper traces: Neural activity recorded from NIf; lower traces: song syllables produced by the bird. (Lower record is baseline during a nonsinging period.) There was a time-locked correspondence of NIf activity and song elements that was qualitatively similar to that seen in HVc (see $D$ and $E$ ). However, NIf activity onset preceded that in HVc. $D$, Multiunit recordings from HVc of the singing zebra finch. Upper trace: Left HVc multiunit activity; lower trace: amplitude envelope of the sound produced by the bird. Units are active before and during vocalization. E. Simultaneous multiunit recordings from HVc and RA, obtained from a singing zebra finch. The records are a continuous temporal sequence, top to bottom. The sound-related activity peaks (in upper record, for example) showed HVc activity onset and termination leading that in RA by several milliseconds, in keeping with the anatomical connections between these nuclei. At the termination of each song rendition, there was a marked repression of activity in RA that decayed gradually over 2-4 sec. During singing periods this repression obscured the large difference in spontaneous activity between $\mathrm{HVc}$ and RA (right half of the lower record). Time bar in $C$ applies to records in $C-E$.

matic song deficits. Five other nuclei are thought to have roles in song development or production because of pathways to or connections from HVc or RA. Recordings were made in each of the 6 forebrain nuclei, aimed first at classifying the nuclei by the presence or absence of neural activity time-locked to song, and second at examining the temporal order in which the various nuclei werc activated prior to sound onset.

Forebrain regions Uva, MAN, and area $\mathrm{X}$ have been included in the vocal control system by virtue of their anatomical connections to HVc or nucleus interfacialis (NIf) and by endocrino- logical and immunocytochemical criteria (Konishi and Akutagawa, 1981; Ryan and Arnold, 1981). For this reason, multiunit recordings were made from these nuclei in the singing zebra finch.

Nottebohm et al. (1982) demonstrated with retrograde HRP transport that nucleus Uva of the thalamus provides the major input to NIf, as well as one of the inputs to HVc. Multiunit recordings from this nucleus were made during both song and calls; these recordings showed no changes in Uva activity related to vocalization, either before or after sound (Fig. 4). There were 
no observable activity variations time-locked to the respiratory rhythm, a possibility suggested by Nottebohm et al. (1982).

The large-celled nucleus MAN showed relatively high signalto-noise ratios among the larger spikes as expected (Fig. 4). By the same token, the small-cell population of area $\mathrm{X}$ was reflected in the relatively undifferentiated recordings from within its borders (Fig. 4). However, both area $\mathrm{X}$ and MAN behaved as if they played no role in adult song production: The recordings showed no consistent changes in baseline firing rates correlated with either song or calls, even in the period of several seconds between introduction of a female into the home cage of the female and the resultant initiation of song. These results are in keeping with pathway lesion cxpcriments discussed below, in which disruption of connections between MAN and HVc, and area $\mathrm{X}$ and $\mathrm{HVc}$, produced no apparent effect on song or the frequency of its delivery (see Fig. 7). Multiunit recordings from 3 nuclei did produce song-related activity; these are now described with attention to the relative timing of activity to sound onset in each.

\section{Source of timing for song control}

\section{NIf multiunit recordings}

This nucleus provides an anatomical input to $\mathrm{HVc}$ and as such might generate bursts of activity that drive the song-correlated activity in HVc. Neural recordings obtained from NIf showed greatly increased neuronal activity temporally correlated with song elements (Fig. $5 A$ ). The song-related pattern of neural activity was manifested by a burst of neural activity that preceded each syllable and an inactive period that preceded each silent interval. The unique pattern of frequency and amplitude modulation characterizing a song syllable was paralleled by a characteristic pattern of neural burst (see Fig. 5C). The distinctions between neural bursts for different syllables, not always evident in filmed oscilloscope traces such as those presented here, were readily apparent when an audio monitor was used. This observation is consistent with the patterns of $\mathrm{HVC}$ single-unit activities described above.

\section{$H V c$ multiunit recordings}

Representative song samples and correlated neuronal activity from $\mathrm{HVc}$ are shown in Figure 5, $D$ and $E$. All neural recordings obtained from within the HVc boundary, in 4 species of songbirds, showed greatly increased neuronal activity temporally correlated with song elements, whereas recordings from just outside $\mathrm{HVc}$ showed no such changes in activity. $\mathrm{HVc}$ recordings showed a pattern of activity similar to that seen in NIf, with time-locked neural bursts clearly leading the onset of sound.

\section{Recordings from $R A$}

Nucleus RA receives a strong descending projection from $\mathrm{HVc}$ and in turn projects to the motor neurons in nXIIts. Involvement of this nucleus in song control has been inferred from its anatomical connections and from the severe disruption of normal song patterning seen after RA lesions (Nottebohm et al., 1976). Recordings obtained simultaneously from HVc and RA in the same zebra finch showed patterned activity, in both nuclei, corresponding to the song pattern (Fig. $5 E$ ). The recordings from $\mathrm{RA}$ were qualitatively similar to those obtained from $\mathrm{HVc}$ in the same bird, and from NIf in different birds, but could be distinguished from them on 2 grounds. First, the rate of spontaneous activity was much higher in RA than in NIf or $\mathrm{HVc}$, so that the signal-to-noise ratio (singing vs nonsinging) was low- er. Second, at song termination there was an obvious cessation of neural activity in RA; this repression or inhibition decays gradually over a period of 2-4 sec. Such repression may well be common in HVc (McCasland and Konishi, 1981) but is much less noticeable because of the large differences in background activity.

\section{Relative timing of activity in NIf, $H V c$, and $R A$}

The relationship between NIf activity and $\mathrm{HVc}$ activity was examined for homologous vocalizations (contact calls) from 2 birds of the same species. When averaged over 25 such comparisons, the onset of NIf multiunit activity led that in $\mathrm{HVc}$ (Fig. 6, $A$ and $B$; 1-way analysis of variance, $F=218.65, p<$ 0.001 ; Mann-Whitney $U, Z=-14.501, p<0.001$ ). The relationship between timing of activity in HVc and RA was examined in similar fashion, using recordings obtained simultaneously from the same subject. Analysis of these data revealed that the activity onset in RA trailed that in both NIf and HVc (NIf-RA: 1-way analysis of variance, $F=552.12, p<0.001$; Mann-Whitney $U, Z=-19.318, p<0.001$; HVc-RA: 1-way analysis of variance, $F=74.12, p<0.001$; Mann-Whitney $U$, $Z=-9.908, p<0.001)$. Figure 6 summarizes the timing data for NIf, $\mathrm{HVc}$, and RA. These findings are consistent with the connections from NIf to $\mathrm{HVc}$ and from HVc to RA, and the absence of reciprocal connections among these nuclei, and suggest a hierarchical organization of the descending motor pathway with NIf at the top of the chain, followed by HVc and then RA.

\section{Lesion experiments}

The multiunit recordings suggested that NIf might play a necessary role in song production. To investigate this possibility lesions were made that eliminated connections between NIf and $\mathrm{HVc}$ in 2 zebra finches. These lesions produced a dramatic behavioral effect; neither of the subjects ever again produced a normal song. Over a period of many months each produced, instead, in the behavioral context of song, a variety of songlike vocalizations (Fig. $7 A$ ), with more complexity and variety than simple call notes strung together but without any stereotyped phrase structure from one rendition to the next. To the ear these "songs" were unlike any produced by normal zebra finches, being highly variable in the form and duration of individual syllables, the inclusion and ordering of selected syllables in the song phrase, and the duration of song. Preoperatively these birds had sung quite normally in all respects, producing a consistent, stereotyped song phrase as shown in the top panel of Figure $7 \mathrm{~A}$. None of the characteristic features of these phrases was preserved following the operation.

To determine whether the behavioral effect of the NIf pathway section experiment was due to surgery alone, an operation was performed on another zebra finch by making the lesion anterior to NIf, so that the descending motor tract was spared. This bird sang normally on the first day after surgery and maintained normal song until sacrificed for histologic examination 2 months later (Fig. 7B); the variation between upper and lower panels is consistent with the normal variation in songs produced by a given individual of this species. Thus, the surgical procedures for this experiment did not in themselves cause any disruption to song. This fact is of additional interest when one considers that the anterior pathway section experiment also eliminated the tracts from MAN to $\mathrm{HVc}_{\text {, }}$ and from $\mathrm{HVc}$ to area $\mathrm{X}$.

The effect of sectioning the NIf projection to $\mathrm{HVc}$ was rem- 

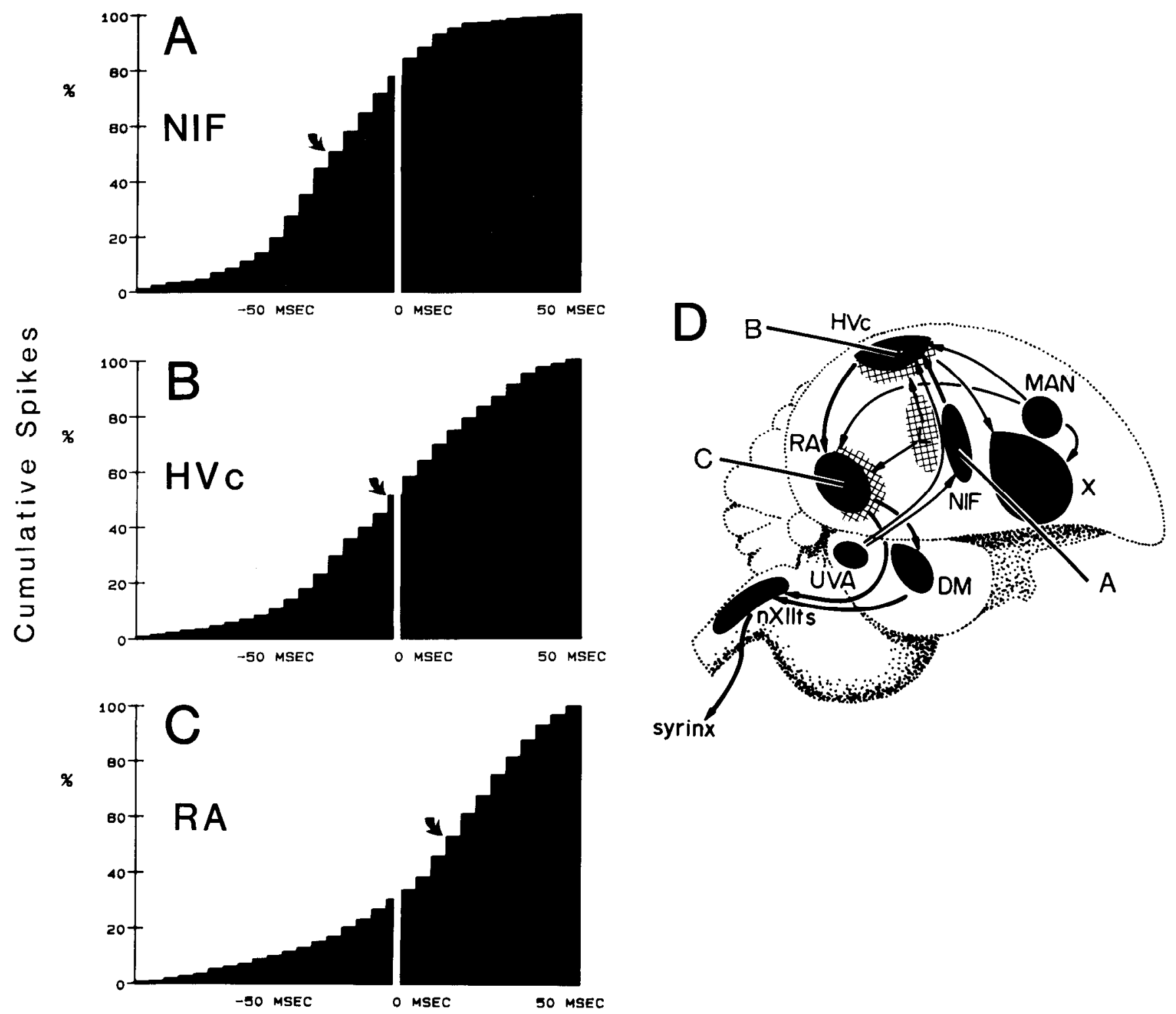

\section{Time Relative to Sound Onset}

Figure 6. Cumulative spike histograms comparing timing of multiunit activity in NIf, HVc, and RA. See anatomical key in $D . A-C$, Cumulative multiunit activity preceding and immediately following sound onset. Vertical lines mark sound onset; black curved arrows indicate time at which $50 \%$ of spikes in the sample have occurred. Approximately $80 \%$ of the spikes in NIf occurred before sound onset; about $55 \%$ of the spikes in HVc and about $35 \%$ in RA preceded vocalization. Half of the spikes in NIf occurred approximately $30 \mathrm{msec}$ before sound onset (compared with about $0 \mathrm{msec}$ in $\mathrm{HVc}$ and about $20 \mathrm{msec}$ after sound onset in RA). These differences were highly significant, demonstrating that NIf activity leads that in HVc, and HVc leads RA, consistent with the descending connections between these nuclei (see key in $D$ ). (For abbreviations in $D$, see legend to Fig. 1.)

iniscent of behavioral deficits reported previously following lesions of $\mathrm{HVc}$ or RA. The finding of early song-related activity in NIf, and the known serial descending connections from NIf to HVc, and HVc to RA, suggested a sequential functional organization of the song control pathway in adults, with NIf serving as a trigger for the timing and ordering of song syllables. But this hypothesis could be correct only if there were no inputs to NIf that might trigger the song-related activity seen there. Two types of experiment were carried out to eliminate this possibility.

As an independent test of the necessity of Uva (the only input to NIf demonstrable with conventional HRP methods) for song, bilateral lesions of Uva were made in 4 zebra finches. In the best case these lesions eliminated approximately $95 \%$ of Uva bilaterally, as well as neighboring nuclei such as nucleus spiriformis. In all cases these lesions, though rather massive, did not affect the normal delivery of song (Fig. 7C) and calls, whereas comparable lesions of $\mathrm{HVc}$ or RA invariably have dramatic effects on song (Nottebohm et al., 1976).

To control for the possibility of input fibers to NIf that do not take up HRP, multiunit recordings were made from sites in the vicinity of NIf. Recordings were obtained from 8 such locations during song and calls in the zebra finch and from 4 such sites in the canary. In all cases these recordings failed to 


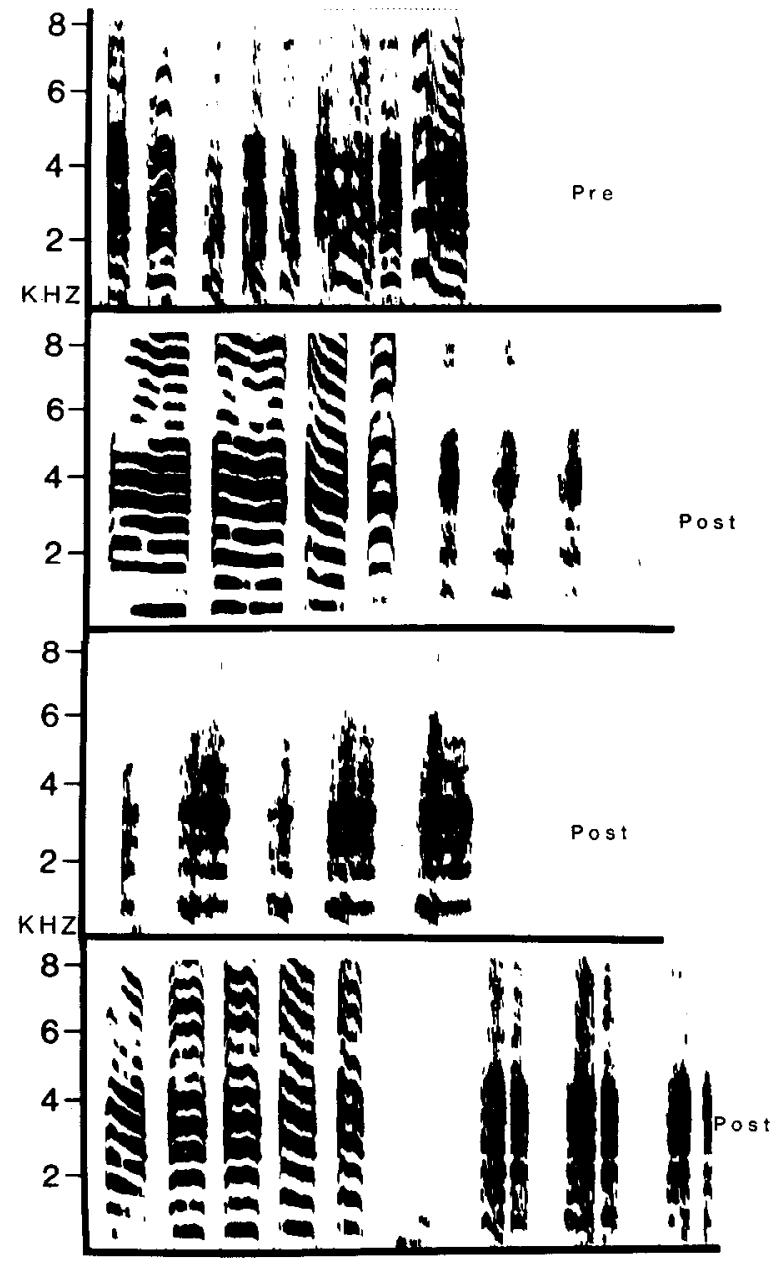

A. NIF Section
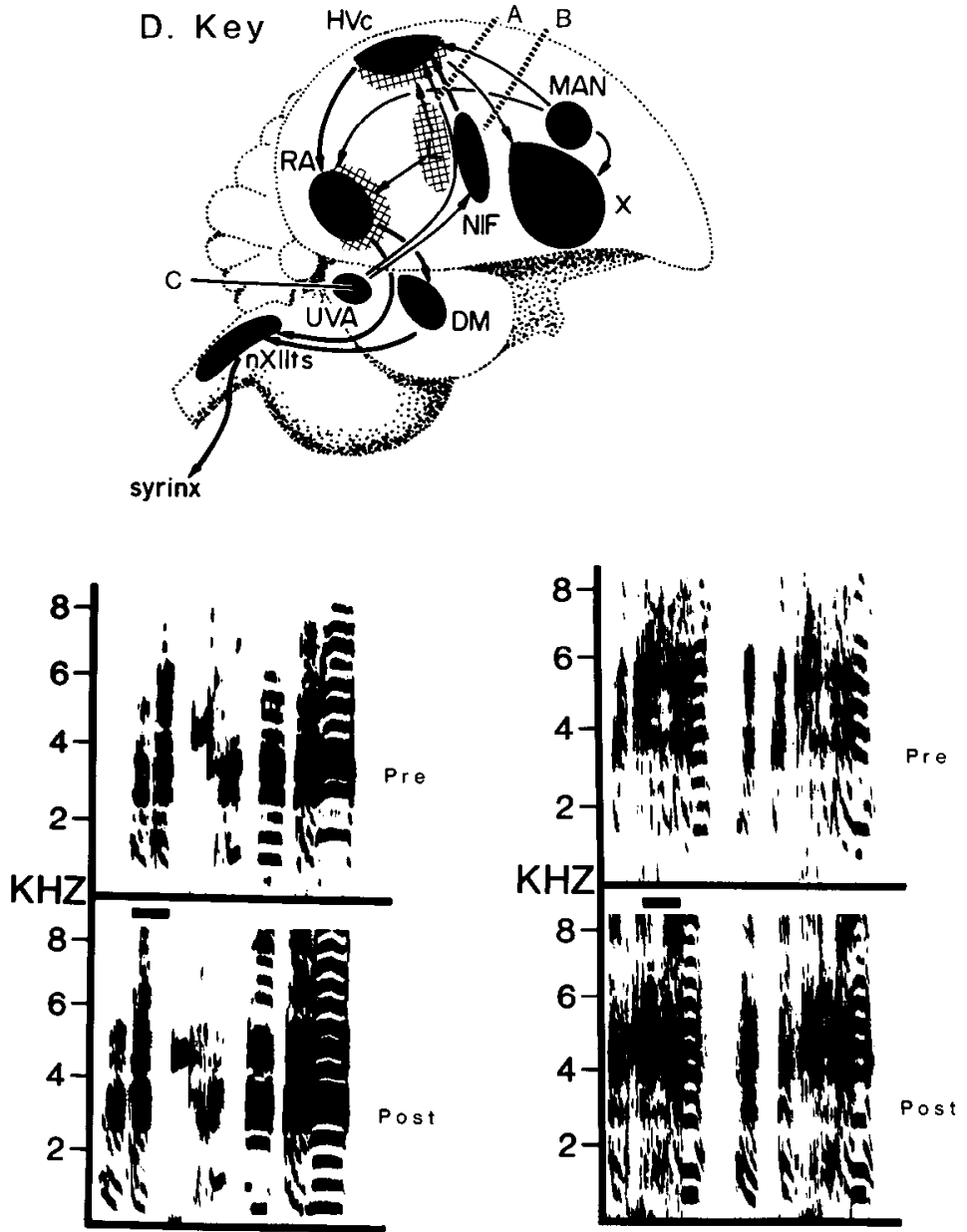

B. Sham Section
C. UVA Lesion

Figure 7. Lesion experiments that (when combined with recordings presented in Figs. 5 and 6) indicate a crucial role for NIf in song production. $A$, Effect on song of sectioning the pathway from NIf to HVc. Upper record: Preoperative sonagram of normal song of a zebra finch. Dashed line indicates a stereotyped song phrase typical of this species. Lower records: Postoperative sonagrams of representative "songs" produced by the same zebra finch after transection of the pathway from NIf to HVc (and the pathway from Uva to HVc, as indicated diagrammatically in $D$ ). These songs carried no stereotyped phrase structure from one rendition to the next, and their component syllables bore no consistent resemblance to those of the preoperative song. $B$, Pre- and postoperative songs corresponding to a sham section comparable to that illustrated in $A$. The incision incidentally eliminated the tract from MAN to $\mathrm{HVc}$, and from $\mathrm{HVc}$ to area X (as shown diagramatically in $D$ ). Nevertheless, the postoperative song phrase (lower sonagram) was unaffected by this surgical procedure. All preoperative syllables (upper sonagram) were preserved in morphology and timing; slight variations in timing of introductory notes are normal in this species. Time calibration, $100 \mathrm{msec}$ (applies to sonagrams in $A$ ). $C$, Effect on song of bilateral lesions of thalamic nucleus Uva. Upper sonagram: Preoperative song of a normal zebra finch; lower sonagram: song produced after bilateral lesions that eliminated approximately $95 \%$ of right and left Uva. Song was unaffected by these lesions, whereas comparable damage to NIf, HVc, or RA invariably had drastic effects on song. All lesions were verified from postmortem histology. Time calibration, 100 msec. D, Dashed and solid lines indicate loci of lesions. (For abbreviations, see legend to Fig. 1.)

show any premotor activity for song or any other vocalizationrelated activity (not shown). Since the multiunit electrode employed must record from a substantial volume of tissue and electrode placements were widely scattered around NIf, it seems safe to conclude that there are no input fibers to NIf, detectable with currently available methods, that relay timing cues for song in the adult. It therefore seems likely that NIf is the highest center for song control in the adult songbird.

\section{Hemispheric dominance in song production}

The findings of differences in onset times of song-related activities in different song control nuclei provide a framework for examining neural correlates of hemispheric dominance in song control. The multiunit technique described above was employed to record bilateral neural activities in individual singing canaries, a species said to be left-dominant because of clear-cut differences in the effects of right or left hypoglossal nerve section (Nottebohm and Nottebohm, 1976) and, to a lesser extent, right or left HVc lesions (Nottebohm et al., 1976).

\section{$H V C$ recordings}

For the same reasons as mentioned in the single-unit results section above, HVc provided the largest number of useful recordings for examining bilateral activity in the singing canary. In each of 3 subjects relatively high-quality recordings were made from both right and left HVc's. The general characteristics of these $\mathrm{HVc}$ recordings conformed to those described above. All recordings obtained within $\mathrm{HVc}$ showed increased neuronal 
A
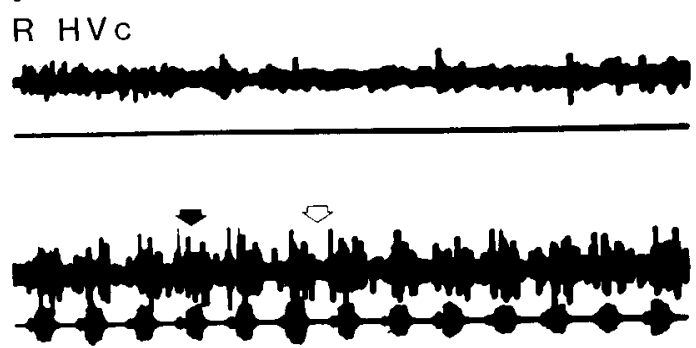

B

R HVC

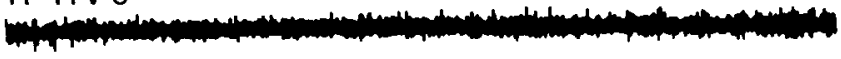

$100 \mathrm{~ms}$
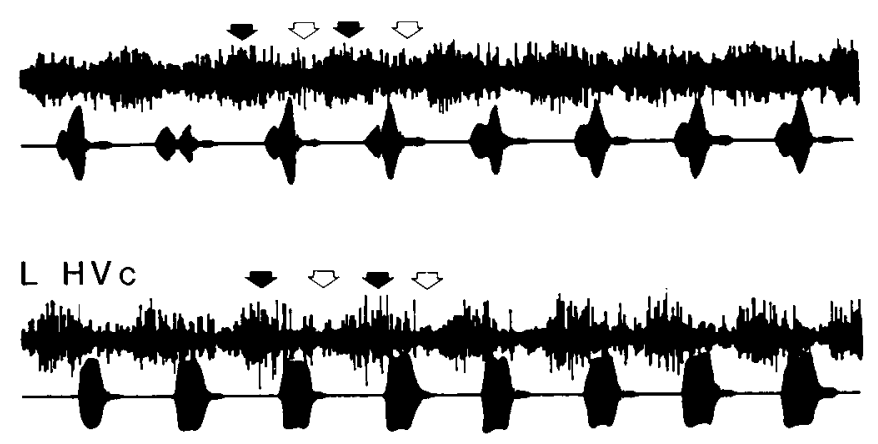

L HVC

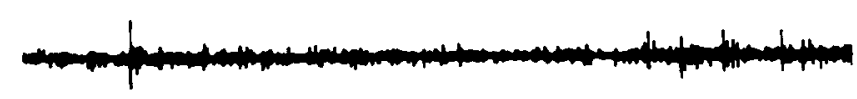

Q

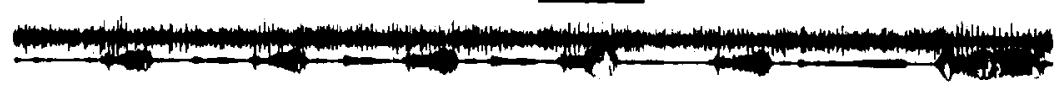

R HVc
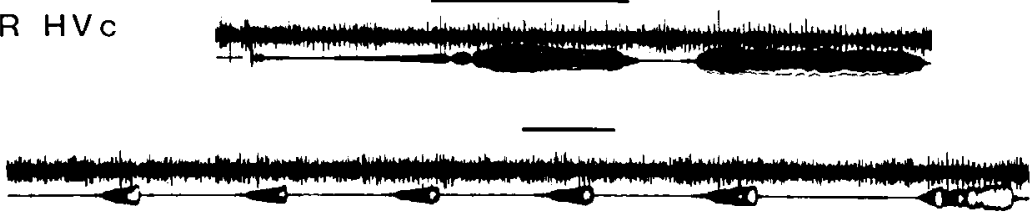

L HVC

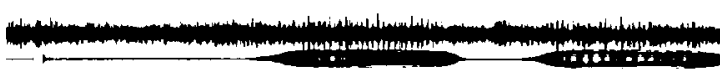

$100 \mathrm{~ms}$

Figure 8. Temporal relationship between neural activity in right and left $\mathrm{HVc}$ of the same bird. Panels represent different subjects. $A$ and $B$, Trill segments, consisting of repeated syllables, produced by normal Wasserschlager canaries, together with multiunit activity recorded from right $\mathrm{HV}$, (upper records) and same trill segments produced by the same subjects, together with left $\mathrm{HVc}$ activity (lower records). The records were processed to remove equal amounts of baseline noise from all traces. For each song syllable, there was a recognizable pattern of activity, consisting of activity bursts (filled arrows) followed by silent gaps (open arrows), which was time-locked to song elements and appeared to be very similar whether recorded from left or right HVc. Time bar applies to both $A$ and $B$. $C$, Terminal song segment, consisting of longer whistled syllables, produced by a normal Wasserschlager canary, together with multi-unit activity recorded from right HVc (upper records) and equivalent terminal segment produced by the same subject, together with left HVc activity (lower records). Solid lines indicate periods of high activity, associated with particular notes, preceded and followed by silent gaps in both right and left HVc. Time calibration, $100 \mathrm{msec}$.

activity time-locked with song syllables, whether those recordings were obtained from the right or left hemisphere. In general, multiunit recordings from right and left $\mathrm{HVc}$ of the same bird showed a striking correspondence in onset time and duration of increased neuronal activity for any given vocalization (Fig. 8). In most canary $\mathrm{HVc}$ recordings, as in the zebra finch recordings described above, the patterns of activity varied systematically from syllable to syllable of a song, a phenomenon easily appreciated by listening to the amplified signals on an audio monitor. In other recordings from different electrode sites, no obvious modulations of pattern could be discerned. This contrast of pattern clarity in different recordings suggests some form of functional topography within $\mathrm{HVc}$, consistent with the specialized single-unit activities described above. However, the presence of obvious patterning was just as likely in right $\mathrm{HVc}$ recordings as in those from the left. Furthermore, in cases where clear patterns could be detected in right and left $\mathrm{HVc}$ of the same bird, those patterns were very similar (Fig. 8). This finding was obtained in the canary, a highly "lateralized" species, as well as in the zebra finch, which is not highly "lateralized" by the same criteria.

In a total of 40 sets of recordings from electrode placements in nuclei of the descending song control pathway, every recording in every set showed activity time-locked to all or almost all song syllables, regardless of the hemisphere from which the recording was made (Table 1 ).

\section{Manipulation of the vocal apparatus}

The finding of similar activity patterns from right and left $\mathrm{HVc}$ of the same bird, together with the fact that no interhemispheric connections have been found (Nottebohm et al., 1982) among any song control nuclei, led to an alternative approach to the 

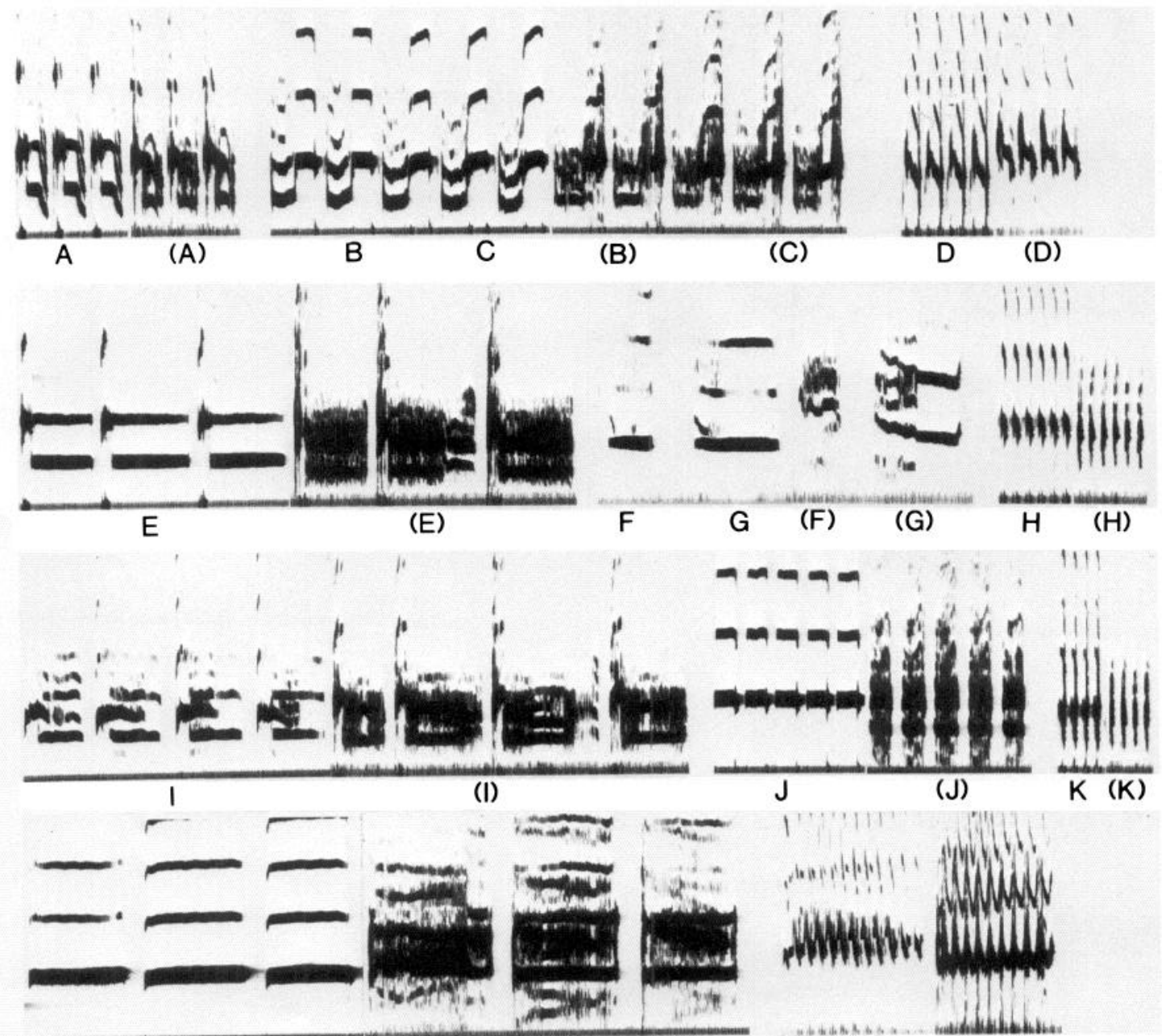

(L)
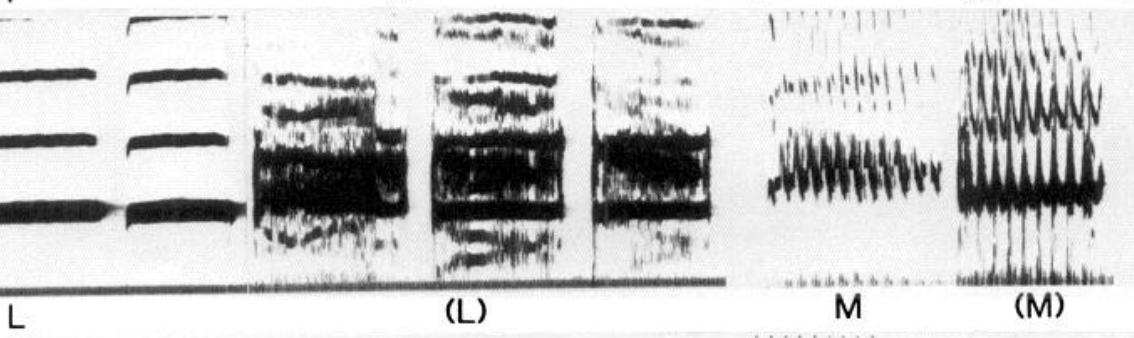

M

$(\mathrm{M})$
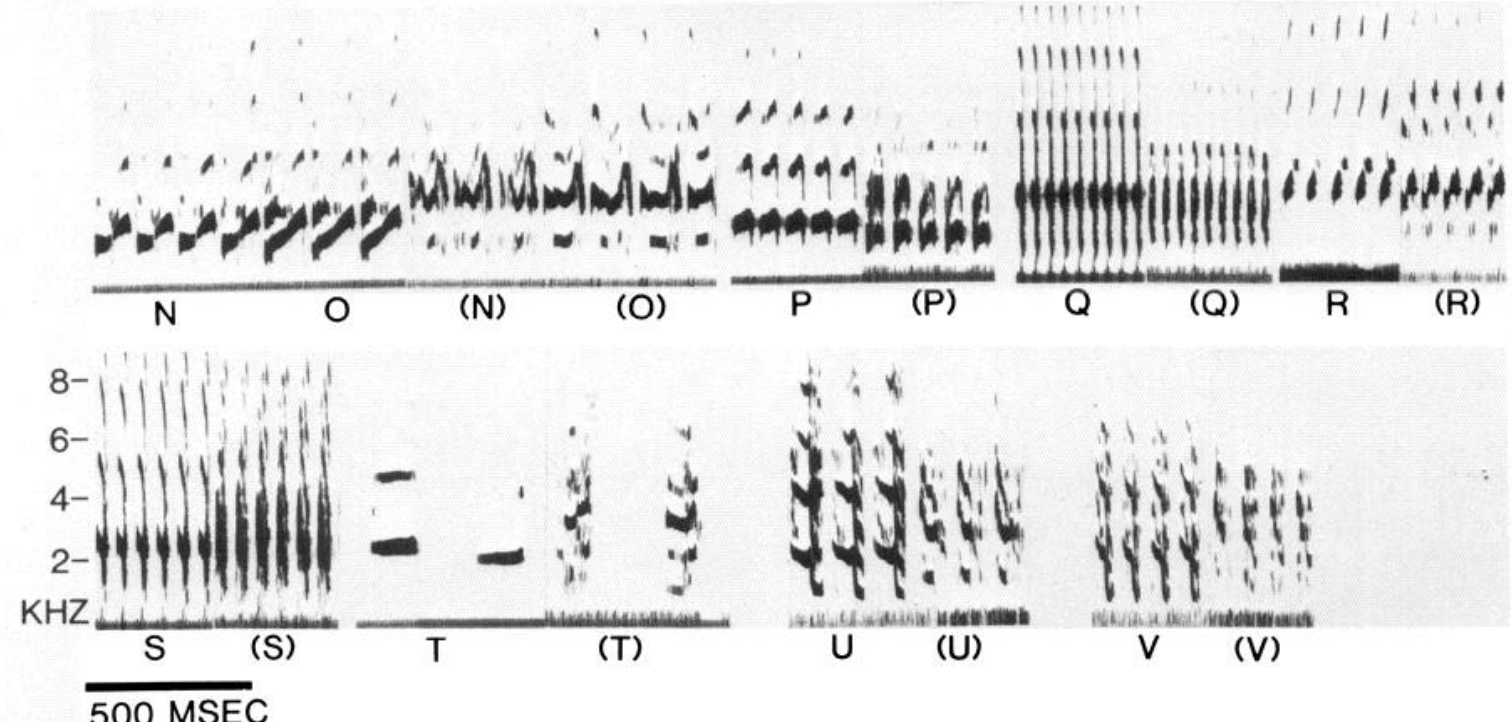

$\overline{500 \mathrm{MSEC}}$

Figure 9. Comparison of song syllables produced by Wasserschlager canaries before and after unilateral bronchus plugging. Left, Sonagrams of song syllables produced by a canary whose left bronchus was plugged (see Fig. 1C), leaving only the right syringeal half in operation. Preoperative syllables are indicated by capital letters; postoperative counterparts are shown in parentheses. In the majority of cases there was an obvious correspondence between pre- and postoperative syllables in both temporal and spectral features; in many cases these matches could be confirmed by the frequency of occurrence of a syllable in song and by the relative position within the song. In at least 2 cases $(G$ and $I)$, the simultaneous 


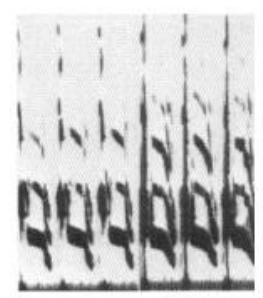

A (A)

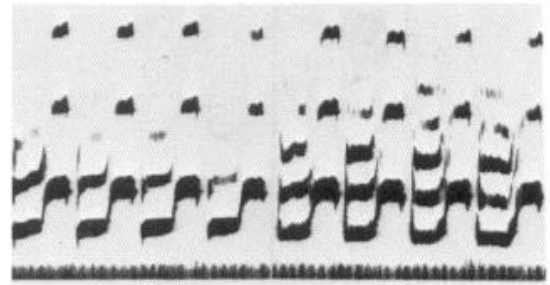

B

(B)
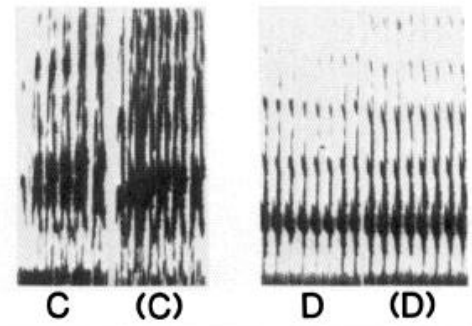

D (D)

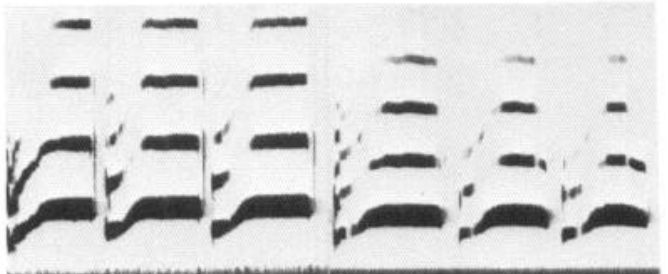

E

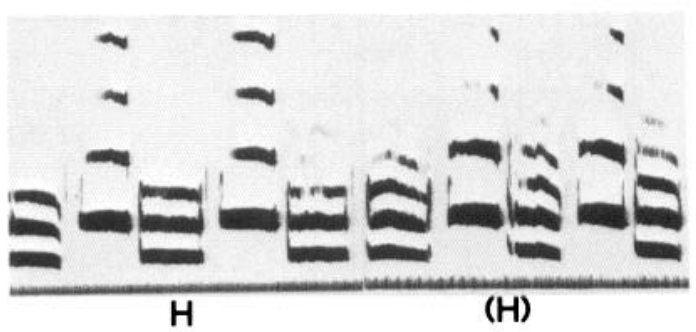

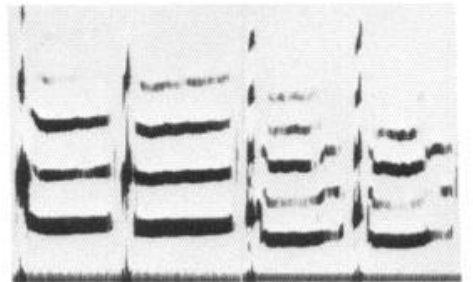

(F)
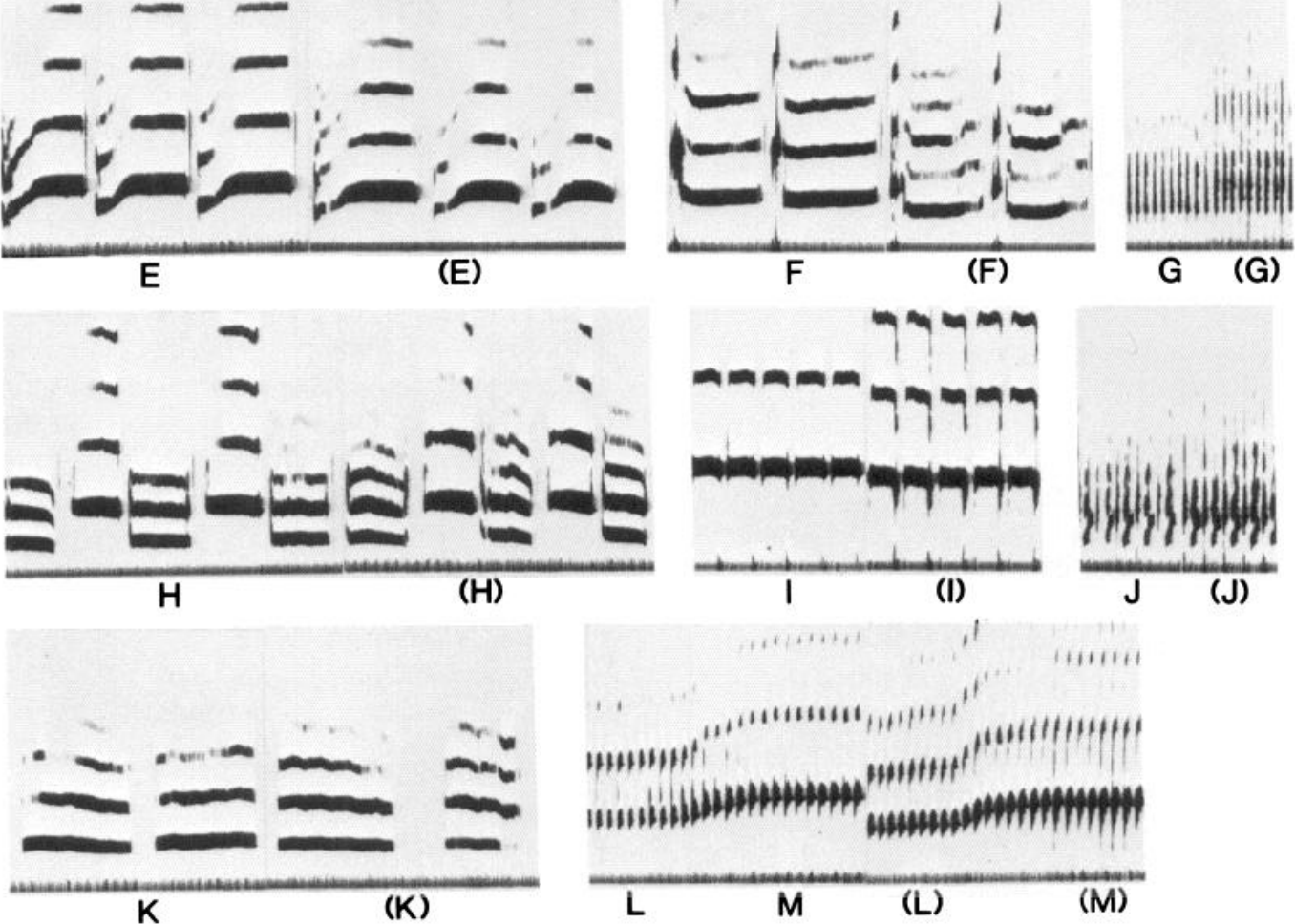

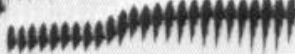

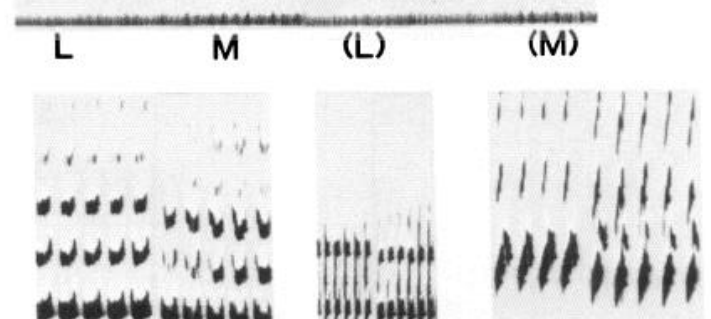

dod vuvyr 내파패

(N)

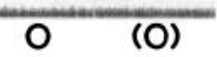

$P(P)$
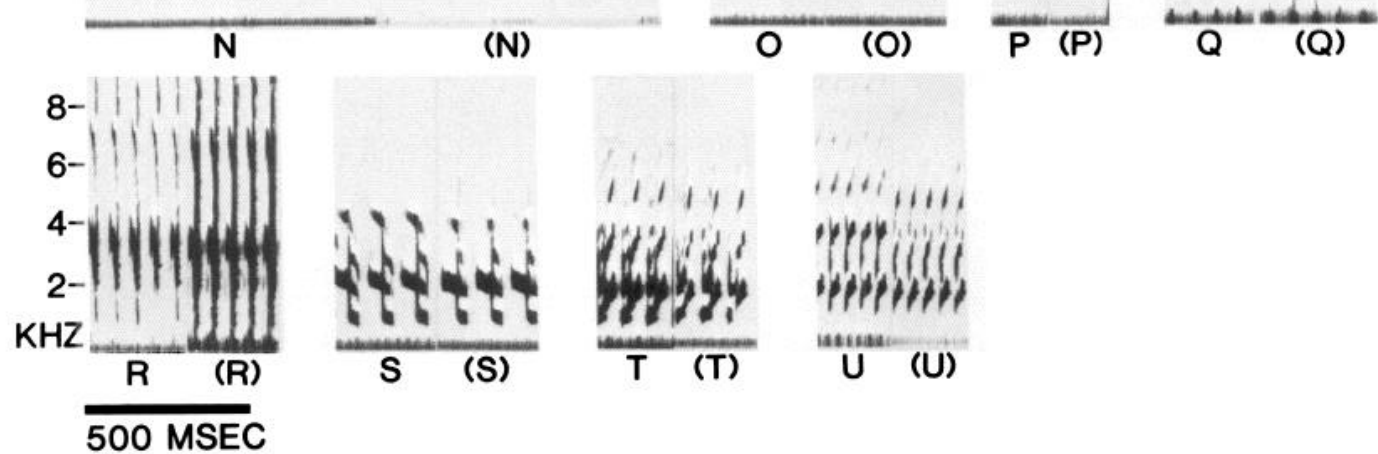

production of 2 fundamentals or voices in postoperative syllables was reminiscent of 2-voice production in the preoperative syllables; this phenomenon appears to be incompatible with the original 2-voice theory of Greenewalt. Right, Song syllables produced by a canary whose right bronchus was plugged, leaving the left syringeal half in operation. Nomenclature is the same as in left. Again, there was an obvious correspondence between most pre- and postoperative syllables, although in this case the distortions produced by the plugging operation were noticeably less severe than those associated with the left bronchus plug. 
issue of hemispheric dominance in song control, the core of which was to find an alternative to hypoglossal denervation as a means of disrupting syringeal function. The disruption of air flow to one bronchus, a technique successfully employed by Suthers and Hector (1982), provided a means of duplicating the logic of the hypoglossal section expcriment whilc imposing a different set of difficulties hindering normal production of sound by the unoperated syringeal half. This experiment therefore served as a second measure of the degree of neural lateralization in song production.

\section{Songs of bronchus-plugged birds}

After the normal songs of subjects were recorded, airflow through the right ( 3 birds) or left ( 4 birds) bronchus was obstructed so that subsequent songs could be produced only by the contralateral syringeal half (see Fig. $1 C$ ). In all cases, the results were qualitatively similar (Fig. 9, $A$ and $B$ ). Following a postoperative recovery period ranging from 4 days to 4 weeks, all subjects produced clear facsimiles of $>85 \%$ of presong syllables. Songs produced by the right-blocked birds, singing with only the left syringeal half, sounded quite normal to the ear except for their reduced amplitude, and close examination of sonagrams revealed only minor distortions in many syllables. Songs produced by left-blocked birds, singing with only the right (presumably nondominant) syrinx, consisted of noisier and more distorted syllables than those produced by right-blocked birds. Nevertheless, these syllables could be easily matched with preoperative syllables by simply listening to them and noting their temporal patterning and position within the song (Guettinger, 1979, 1981). The overall repertoire size in all cases remained essentially constant, with some variability in this measure being introduced by rarely voiced syllables that may have been missed in the preoperative or postoperative song sample. Songs produced exclusively by the left or right syrinx were of normal length (many in excess of $20 \mathrm{sec}$ ), and as can be seen from a pre- and postoperative comparison in Figure 9, the syllables were spaced at normal intervals. Significantly, these birds were able to produce with 1 bronchus syllables containing 2 simultaneous nonharmonically related sounds [see $G,(G)$ and $I,(I)$ of Fig. 9, left].

\section{Discussion}

Four major conclusions are supported by these results. First, the telencephalic nucleus HVc has a substantial number of functionally distinct single units, as demonstrated by their activity patterns recorded during song. Second, NIf provides signals to lower stations in the descending motor pathway, via its output tract to $\mathrm{HVc}$, and appears to be a source of timing cues for song control. Third, multiunit recordings show that NIf, $\mathrm{HVc}$, and RA are sequentially activated prior to song onset, consistent with the known connections of these nuclei and with the concept of a hierarchical organization of the song control system. Fourth, as judged by bilateral central recordings and unilateral peripheral disruption, both right and left HVc's and syringeal halves appear to make similar contributions to most song syllables. Thus, the analogy between the dominance in song control and the neural lateralization of human speech should be viewed with caution.

\section{Single-unit activity in HVc during song production}

$\Lambda$ mong the attractions of the bird song system is its ability to store a complex auditory input as a "template" during 1 phase of the animal's life and to use the template, by means of auditory feedback, to mold a matching complex motor output (Konishi, 1965). At least in formal terms, human speech and many other complex human behaviors involve analogous stages of template storage and feedback-mediated matching of motor output (cf. Marler, 1981). The ncural processes by which bird song is developed and produced may therefore serve as a useful animal model for the development and production of complex motor behaviors. The inputs to and outputs from the song system can be studied and manipulated much more easily than is ordinarily the case in the study of such behaviors. In this context, the specialized patterns of activity seen in HVc single-unit recordings take on particular interest. Although a detailed discussion of human motor cortex and its role in the generation of complex movements is beyond the scope of this report, it should be noted here that there remains much confusion about functional aspects of this system (for a recent review, see Wise, 1985). Although best evidence suggests a role for premotor cortex in the preparation for and the sensory guidance of movement, little is known about the ways in which individual neurons might be specialized to carry out such functions. The sample of single units showing specific relationships to the performance of one of a set of closely related complex behaviors, analogous to the specific activity patterns shown above, is as yet quite small (e.g., Wise, 1985). It should be possible, with further single-unit recordings of the type presented here, to characterize a set of unit populations, station by station in the vocal control system, whose specific activity patterns can be easily related to the behaviorally derived functional requirements of song development and production.

\section{Source of timing cues for song control}

\section{Assessment of the roles of song control nuclei}

The complexity of song consists in the structure of its sound elements, as well as in their sequencing and timing. Although it is not yet possible to make predictions about the detailed relationships between the activities of particular nuclei and the characteristics of the sounds produced, it is clear that there is a consistent correspondence between the pattern of multiple-unit discharge in NIf, HVc, and RA, and the timing of song elements. No such correspondence was found for MAN, area X, or Uva. This finding, when taken in conjunction with the song deficits seen following lesions involving NIf, HVc, and RA (Nottebohm et al., 1976; and above), implies that in the adult each of these latter 3 nuclei either generates or relays learned temporal cues for song.

Multiunit recordings from the same electrode locations that show song-related activity also show activity associated with production of calls. Song is learned by males and requires auditory feedback for its normal development, whereas calls in most species studied do not require learning from other birds (Lanyon, 1960). Thus, cells recorded from the same site were involved in production of both the learned patterns of song and the unlearned patterns of calls. Whether separate groups of cells encode the 2 kinds of patterns must await a more complete survey of single-unit activities than that presented here.

Nottebohm et al. (1976) inferred from their lesion studies that $\mathrm{HVc}$ was the highest center for song control and from logical considerations and other evidence concluded that song-learning processes take place in this nucleus. Indeed, several lines of evidence show a correlation between anatomical features of $\mathrm{HVc}$ and behavioral indices of song learning. The volume of $\mathrm{HVC}$ fluctuates seasonally (Nottebohm, 1981), corresponding to the 
presence and absence of singing behavior, and is dramatically larger in males than in females, which do not sing or sing much less than males (Nottebohm and Arnold, 1976; Gurney and Konishi, 1980). Furthermore, there is a correlation between the volume of $\mathrm{HVC}$ and the size of song repertoire (Nottebohm et al., 1981). However, the classical lesion studies that demonstrated the necessity of $\mathrm{HVc}$ for normal song are also subject to a general limitation of lesion studies: any input tract to $\mathrm{HVc}$ would be effectively eliminated by the same lesion. The lesion experiments, therefore, do not by themselves allow a determination of which vocal control nucleus generates, as opposed to transmits, song-correlated patterns of activity.

The logical first step in characterizing the roles of various stations in the vocal control pathway is to establish which station in the descending pathway generates the earliest functional activity time-locked to song syllables. This station presumably serves as the effector or initiator of the timed pulses of neural activity that generate song. Because the ordering and intersyllable intervals of song are traits acquired during development, the highest station in the control pathway must in a sense embody the acquired rhythm of the song. The present results do not assess the developmental events by which the "program" of song was established, but they can pinpoint the station that, in the adult, generates the acquired code.

These considerations lead to the following set of requirements which must be met before a nucleus can be considered a source of timing cues for song. First, the pattern of neural activity it produces must be correlated with the temporal pattern of song. The multiunit recordings presented here show such time-locking for NIf, HVc, and RA. Second, the presound onset of increased discharge in the candidate nucleus must be earlier than that in other nuclei. NIf activity in the zebra finch satisfies this requirement by leading that in both $\mathrm{HVc}$ and RA. Third, removal of the nucleus from the song-production circuit should produce song deficits. Section of the pathway from NIf to HVc leads to disruption of normal song, while comparable sham surgery has no such effect. Finally, the sources of input fibers to the nucleus should not produce song-related activity or be necessary for song production. The present study includes 3 experiments to satisfy these conditions for thalamic nucleus Uva, and for any other NIf inputs to which conventional HRP methods might be insensitive. Uva recordings did not show song-related activity, and Uva lesions did not disrupt song. Multiunit recordings from 12 widely scattered locations around the vicinity of NIf also consistently failed to show song-related activity. It is not known whether NIf cells receive input from adjacent Field $L$, the avian homolog of auditory cortex.

Multiunit recordings in NIf of the zebra finch showed clear responses to clicks and other stimuli, but it is possible that the activities of nearby Field $L$ neurons were represented. While some recordings from Field $\mathrm{L}$ neurons of the singing canary do show bursts of activity following song syllables (unpublished observations), there have been no observed instances of activity leading vocalization in this nucleus. It seems safe to assume that any input to NIf from Field L would constitute auditory feedback and could be generated only after the initiation of sound output. It follows that inputs from Field L could not account for the presound onset of activity in NIf and other nuclei. It is well established that deafening does not affect song patterning, at least in some species, if performed in the adult after song crystallization. I have previously shown that $\mathrm{HVc}$ in a bird so treated produces normal song-related activity patterns
(McCasland and Konishi, 1981), and in view of the above discussion, it seems safe to assume that NIf does as well. The present results demonstrate that NIf is the first site in the descending motor pathway where one can observe a pattern of neural activity corresponding to the song pattern. It is very likely that NIf functions as a source of timing cues for song.

Lesions of the 3 song control nuclei that showed no songlocked neural activity-Uva, MAN, and area X-or the pathways linking them to the descending motor pathway, had no effect on song (above and Nottebohm et al., 1976). Thus, the present experiments demonstrate that lesion effects provide a better indication of the necessity of a nucleus for adult song production than do studies of anatomical connections. Whether Uva, MAN, and/or area $X$ plays a role in song development (such a role has been suggested for MAN by Bottjer and Arnold, 1982) remains to be determined.

The present study illustrates that the 3 serially connected telencephalic nuclei of the descending motor tract-NIf, HVc, and RA-are activated sequentially, in descending order, prior to song onset. The combined use of neurophysiological recordings and lesion-behavior experiments shows that NIf provides an input tract to $\mathrm{HVc}$, is thus "higher" in the descending motor tract, and is uniquely placed to be the effector nucleus as the source of timing cues for song. These results, along with extensive anatomical observations (Nottebohm et al., 1982) are consistent with a hierarchical organization, in the adult, of the motor system for song control. This notion is consistent with evidence from other motor systems such as motor cortex in the monkey (for a recent review, see Evarts et al., 1984).

\section{Reassessment of hemispheric dominance in song control Bilateral neural recordings}

The simplest neural correlate of hemispheric dominance would be the presence of activity during vocalization in the dominant side and absence of activity in the other side; this may be referred to as the "all-or-nothing" mechanism of lateralization. No such absence of activity during vocalization was noted in 40 sets of multiunit recordings from right or left NIf, HVc, or RA in 4 species of birds (Table 1 ). In recordings made simultaneously from right and left $\mathrm{HVc}$ of individual "highly lateralized" canaries there was a close correspondence in premotor onset time and durations of song-related activity and a close similarity in the temporal patterns of right and left discharge for any given vocalization (Fig. 7). Indeed, in at least 1 example, it appeared that song-related patterning was more clear-cut in the right $\mathrm{HVc}$ than in the left (Fig. 8A); such slight differences were probably due to differences in electrode geometry and placement. These data suggest that both right and left $\mathrm{HVc}$ could be transmitting similar messages to their respective syringeal halves. At the very least, these results are incompatible with any all-or-nothing mechanism of lateralization in the song control system.

A more subtle form of neural asymmetry may involve different numbers of neurons performing different roles in the neuromuscular control of the syrinx. In practice, this possibility can never be eliminated. As previously discussed, single-unit recording from $\mathrm{HVc}$ of a singing mockingbird revealed units possessing different patterns of discharge with reference to the temporal pattern of song; some neurons fired prior to all vocalizations, while others fired only for specific song syllables (Figs. 2, 3). The discharge patterns of these specialized neurons would have been completely masked in multiunit recordings from $\mathrm{HVc}$. Nevertheless, the absence of clear-cut hemispheric asymmetry 
in multiunit $\mathrm{HVc}$ recordings suggested that both syringeal halves were normally involved in the production of all song syllables. The bronchus-plugging experiments served as a direct test of this hypothesis.

\section{Direct assessment of unilateral syringeal function}

The absence of interhemispheric connections in the song control system (Nottebohm et al., 1982) is a key to interpreting the present results. Because of this, if there is true hemispheric dominance in song production, then each "voice" in any given song syllable must be contributed by one hemisphere or the other, but not both. The denervation results support this idea by showing complete elimination of some syllables; the fact that many syllables are rendered postoperatively in distorted form can be explained as an epiphenomenon of the surgery, such as the production of sound by the normally silent syringeal half. But the same type of result, obtained in the bronchus-plugged bird, forces a reevaluation of the basis for the distorted syllables, since it is much less likely that they can be simply an epiphenomenon of the surgery. The right syrinx of the canary, working alone, produces a train of syllables the timing of which is identical to normal song and the majority of which bear a striking element-by-element resemblance to those in the preoperative song. These birds were also able to produce with 1 bronchus syllables containing 2 simultaneous nonharmonically related sounds $[G,(G)$ and $I,(I)$ of Fig. 9, left], indicating that the simplest application of the Greenewalt 2-voice theory of syringeal function to the cerebral dominance hypothesis - that 1 voice of each 2-voice syllable is produced by each syringeal half (Greenewalt, 1968; see also Stein, 1968)-is not applicable (at least in this case). Since all of the qualitative features of the preoperative syllables-duration, interval, frequency modulation, complex elements, 2 voices-are present in many of the syllables produced after plugging either right or left bronchus, it is quite likely that both hemispheres and syringeal halves normally participate in the production of these features.

This conclusion is consistent with and clarifies the interpretation of the bilateral $\mathrm{HVc}$ recordings. Because of the absence of crossing connections, it is very unlikely that the activity recorded in right HVc can be a reflection of some "tonic" role for that nucleus in song production. Despite uncertainties about the mechanisms of sound production by the syrinx, the simplest interpretation of available data is that the right $\mathrm{HVc}$ activity serves to drive the right syrinx in analogous fashion to the manner in which left HVc drives the left syrinx. If this is true, then one would expect to find a similar assortment of specialized single units in right and left $\mathrm{HVc}$, discharging in concert for any given song segment. Song-specific auditory units (Margoliash, 1983 ) and units showing motor-auditory interactions (above; see also McCasland and Konishi, 1981) should be bilaterally distributed as well. In this interpretation it is also likely that differences in distortion levels in songs produced after bronchus plugging are due largely or entirely to peripheral factors such as differential responses to loading, asymmetric airflow patterns, strengths of muscular contractions, etc.

As mentioned above, there is a correlation in the canary between the volume of $\mathrm{HVc}$ and the size of the song repertoire. If the size of HVc can serve as an index of song learning or degree of involvement in song production, the lateralization theory would predict left-right anatomical differences in the vocal control nuclei. No such differences are present in HVc (Nottebohm et al., 1981) or any other vocal control nuclei except the hypoglossal motor nucleus, where the left side is larger than the right by $6 \%$ (Nottebohm and Arnold, 1976), a difference consistent with the difference in syringeal muscle mass. A detailed analysis of neuronal morphology of RA, which demonstrated clear male-female differences, did not find any left-right bias (DeVoogd and Nottebohm, 1981), and an ultrastructural analysis of the hypoglossal nucleus also failed to show significant right-left differences ( $T$. J. DeVoogd, personal communication).

Some $\mathrm{HVc}$-lesioned canaries showed fewer changes in their songs than hypoglossus-lesioned birds (Nottebohm and Nottebohm, 1976; Nottebohm et al., 1976; Nottebohm, 1980). This difference may be due to the fact that a peripheral nerve can be lesioned more surely than a brain nucleus. Also, the hypoglossal nerve contains neurons that cause the syringeal muscles to contract in synchrony with the respiratory rhythm (Manogue and Paton, 1982). Cutting these fibers may disrupt the coordination between respiration and vocalization, whereas a lesion of $\mathrm{HVc}$ might not affect this aspect of vocal control. It seems quite unlikely that the difference in effects of $\mathrm{HVc}$ lesions and hypoglossal section is due to dominance-related factors.

It is also unlikely that our left-plugged birds were actively modifying the motor program for song so as to produce more syllables with the "subordinate" right side. Nerve-sectioned birds did not show recovery of preoperative syllables over the same time course for which the bronchus-plugged birds were recorded (Nottebohm and Nottebohm, 1976). In another study, birds whose left hypoglossi were sectioned at 1 year of age and who were recorded a year later showed recovery of very few preoperative elements, even in modified form (Nottebohm et al., 1979).

\section{Reversal of hypoglossal dominance: A reinterpretation}

Nottebohm et al. performed a series of unilateral denervation studies to examine developmental aspects of hypoglossal dominance. These studies demonstrated that canaries could develop song under right "dominance" following left hypoglossal section early in the subject's life. In all cases in which the syringeal muscles were examined following reversal of dominance, there was a clearly visible atrophy of the muscles on the denervated side, constituting a reversal of the normal peripheral asymmetry. Comparable measurements of the volumes of left and right song control nuclei were not made. However, the present results and the absence of hemispheric volume differences in normal canaries suggest a different interpretation of dominance reversal. All of the reversal data can be explained as easily by peripheral as by central mechanisms. One can think of these experiments as a rough assay of the right-left distribution of muscle mass in the syrinx. Presumably this distribution in the adult is differentially affected by hypoglossal nerve section done at various developmental stages.

\section{Concluding remarks}

Because the effect of lesioning left or right $\mathrm{HVc}$ can be measured only by assessing deficits in vocal output, a functional dominance at any level in the vocal control system would be invoked in any such measurement. This implies that lesion of HVc cannot be used to pinpoint the site of functional dominance. Similarly, the destruction of the left hypoglossal nerve does not allow one to distinguish between lateralization of activity in the 2 nerves and/or lateralization of the strengths of muscular contractions (which may be identically timed and patterned in the normal case) in the syrinx. How and why the muscular asymmetry develops in the ontogeny of an individual or a species is an unanswered question. Some unknown central asymmetry 
may drive the 2 sides differently, or it may develop in response to differential loading by the periphery. By analogy with humans it may be that development of syringeal positioning and/or geometry is partially dependent on the positioning of the visceral organs. If this is so, it is possible that some measurable index of syringeal position or geometry will accurately predict the degree of "lateralization" seen following hypoglossal section.

The degree of lateralization as measured by nerve-section results does not seem to be correlated with other anatomical or behavioral aspects of song, aside from the degree of asymmetry in the syrinx. Hypoglossal dominance is exhibited by canaries that had no access to auditory feedback, necessary for normal song development (Konishi, 1965). The ability to imitate song does not seem to be correlated with degree of lateralization; an asymmetry is barely noticeable in the song of the zebra finch, which imitates song well (Price, 1977). The degree of dominance is unaffected by unilateral cochlear removal before song development (Nottebohm and Nottebohm, 1976); thus there is no evidence of asymmetry in the underlying processing of auditory inputs. Vocal repertoire size is essentially normal in canaries that have had early left hypoglossal section and have developed song under right hypoglossal control. Observations on several species of songbirds suggest that the extent of dominance is uncorrelated with size of vocal repertoire, duration of critical period, or extent of auditory experiences.

The following hypothesis can account for all of the lateralization results presented here, and could serve as a framework for future investigations. Individual song syllables are produced by the combined actions of the right and left vocal control systems. Although each syringeal half can work in the absence of the other half, the 2 sides are normally coordinated to produce qualitatively similar sounds. The relatively subtle left-right asymmetry in the effects of bronchus plugging can be accounted for by assuming that the left bronchus provides a greater driving force than the right one, so that sounds of greater amplitude are produced in the left syrinx. In this view the lateralization of song control in birds is quantitative rather than qualitative, in contrast with neural control of human speech in which fundamental qualitative as well as quantitative differences are known for the 2 brain hemispheres (reviewed by Damasio and Geschwind, 1984).

\section{References}

Bottjer, S. W., and A. D. Arnold (1982) Afferent neurons in the hypoglossal nerve of the zebra finch (Poephila guttata): Localization with horseradish peroxidase. J. Comp. Neurol. 210: 190-197.

Damasio, A. R., and N. Geschwind (1984) The neural basis of language. Annu. Rev. Neurosci. 7: 127-147.

DeVoogd, T. J., and F. Nottebohm (1981) Sex differences in dendritic morphology of a song control nucleus in the canary. A quantitative Golgi study. J. Comp. Neurol. 196: 309-316.

Evarts, E. V., Y. Shinoda, and S. P. Wise (1984) Neurophysiological Approaches to Higher Brain Functions, Wiley, New York.

Gaunt, $\Lambda$. S. (1983) $\Lambda$ n hypothesis concerning the relationship of syringeal structure to vocal abilities. Auk 100: 853-862.

Greenewalt, C. H. (1968) Bird Song, Acoustics and Physiology, Smithsonian Institution Press, Washington, D.C.

Guettinger, H. E. (1979) The integration of learned and genetically programmed behavior: A study of hierarchical organization in songs of canaries, greenfinches and their hybrids. Z. Tierpsychol. 49: 285303.

Guettinger, H. E. (1981) Self-differentiation of song organization rules of deaf canaries. Z. Tierpsychol. 56: 323-340.

Gurney, M. E., and M. Konishi (1980) Hormone-induced sexual differentiation of brain and zebra finches. Science 208: 1380-1382.

Konishi, M. (1965) The role of auditory feedback in the control of vocalization in the white-crowned sparrow. Z. Tierpsychol. 22:770 783.

Konishi, M., and E. Akutagawa (1981) Androgen increases protein synthesis within the avian brain vocal control system. Brain Res. 222. 442-446.

Lanyon, S. (1976) Development of song in a mockingbird hand-reared from the egg in a controlled auditory environment. Kingbird 26: 4 10.

Lanyon, W. E. (1960) The ontogeny of vocalization in birds. In Animal Sounds and Communication, W. E. Lanyon and W. N. Tovolga, eds., pp. 231-347, American Institute of Biological Sciences, Washington, D.C.

Manogue, K., and J. Paton (1982) Respiratory gating activity in the avian vocal control system. Brain Res. 257: 383-387.

Margoliash, D. (1983) Acoustic parameters underlying the responses of song-specific neurons in the white-crowned sparrow. J. Neurosci. 3: 1039-1057.

Marler, P. (1970) A comparative approach to vocal learning: Song development in white-crowned sparrows. J. Comp. Physiol. Psychol. 71(2): $1-25$.

Marler, P. (1981) Birdsong: The acquisition of a learned motor skill. Trends Neurosci. 4: 88-94.

Marler, P., and M. Tamura (1964) Culturally transmitted patterns of vocal behavior in sparrows. Science 146: 1483-1486.

McCasland, J. S., and M. Konishi (1981) Interaction between auditory and motor activities in an avian song control nucleus. Proc. Natl. Acad. Sci. USA 78: 7815-7819.

Nottebohm, F. (1971) Neural lateralization of vocal control in a passerine bird. I. Song. J. Exp. Zool. 177: 229-262.

Nottebohm, F. (1972) Neural lateralization of vocal control in a passerine bird. II. Subsong, calls and a theory of vocal learning. J. Exp. Zool. 179: 35-50.

Nottebohm, F. (1977) Asymmetries in neural control of vocalization in the canary. In Lateralization in the Nervous System, S. Harnad, R. W. Doty, L. Goldstein, J. Jaynes, and G. Krauthamer, eds., pp. $23-$ 44, Academic, New York.

Nottebohm, F. (1980) Brain pathways for vocal learning in birds: A review of the first 10 years. Prog. Psychobiol. Physiol. Psychol. 9. 85-124.

Nottebohm, F. (1981) A brain for all seasons: Cyclical anatomical changes in song control nuclei of the canary brain. Science 214:13681370 .

Nottebohm, F., and A. P. Arnold (1976) Sexual dimorphism in vocal control areas of the songbird brain. Science 194: 211-213.

Nottebohm, F., and M. E. Nottebohm (1976) Left hypoglossal dominance in the control of canary and white-crowned sparrow song. $J$. Comp. Physiol. 108: 171-192.

Nottebohm, F., T. M. Stokes, and C. M. Leonard (1976) Central control of song in the canary, Serinus canarius. J. Comp. Neurol. 165: 457-486.

Nottebohm, F., E. Manning, and M. E. Nottebohm (1979) Reversal of hypoglossal dominance in canaries following unilateral syringeal denervation. J. Comp. Physiol. 134: 227-240.

Nottebohm, F., S. Kasparian, and C. Pandazis (1981) Brain space for a learned task. Brain Res. 213: 99-109.

Nottebohm, F., D. B. Kelley, and J. A. Paton (1982) Connections of vocal control nuclei in the canary telencephalon. J. Comp. Neurol. 207: 344-357.

Price, P. H. (1977) Determinants of acoustical structure in zebra finch song. Ph.D. thesis, University of Pennsylvania.

Ryan, S. M., and A. P. Arnold (1981) Evidence for cholinergic participation in the control of bird song: Acetylcholinesterase distribution and muscarinic receptor autoradiography in the zebra finch brain. J. Comp. Neurol. 202: 211-219.

Stein, R. C. (1968) Modulation in bird sounds. Auk 85: 229-243.

Suthers, R. A., and D. H. Hector (1982) Mechanism of the production of echolocating clicks by the grey swiftlet, Collocalia spodiopygia. J. Comp. Physiol. 148: 457-470.

Thorpe, W. H. (1958) The learning of song patterns by birds, with especial reference to the song of the chaffinch, Fringilla coelebs. Ibis 100: $535-570$.

Wise, S. P. (1985) The primate premotor cortex: Past, present, and preparatory. Annu. Rev. Neurosci. 8: 1-19.

Wolbarsht, M. L., E. F. MacNichol, and H. G. Wagner (1960) Glass insulated platinum microelectrode. Science 132: 1309-1310. 